\title{
Hand Masses
}

James Teh, MBBS, MRCP, FRCR ${ }^{1}$ Maryam Shahabpour, MD ${ }^{2}$ Jean-Luc Drape, MD $^{3}$

Antoine Feydy, MD, PhD $^{3}$ Iwona Sudoł-Szopińska, MD, PhD ${ }^{4}$ Filip M. Vanhoenacker, MD, PhD

1 Department of Radiology, Nuffield Orthopaedic Centre, Oxford University

Hospitals NHS Foundation Trust, Headington, Oxford, United Kingdom

Address for correspondence James Teh, MBBS, MRCP, FRCR, Radiology Department, Nuffield Orthopaedic Centre, Oxford

2 Department of Radiology, Universitair Ziekenhuis Brussel, University Hospitals NHS Foundation Trust, Windmill Road, Brussels, Belgium

${ }^{3}$ Department of Radiology, Cochin Hospital, Paris, France

${ }^{4}$ Department of Radiology, National Institute of Geriatrics, Headington, Oxford OX3 7LD, United Kingdom

Rheumatology and Rehabilitation, Warsaw, Poland

${ }^{5}$ Department of Radiology, Ghent University Hospital, Ghent, Belgium

(e-mail: jamesteh1@gmail.com).

Semin Musculoskelet Radiol 2021;25:216-231.

\begin{abstract}
Keywords

- hand and wrist tumor

- mass

- magnetic resonance imaging

- ultrasound

Hand and wrist soft tissue masses may be classified as pseudotumors, benign neoplasms, or malignant neoplasms. The vast majority of hand lesions are benign. Consideration of the location of the lesion and its imaging characteristics often leads to a specific diagnosis. Pseudotumors discussed in this article are ganglion cysts, accessory muscles, and inflammatory lesions. True tumors are described according to their tissue type: nerve sheath tumors, adipocytic tumors, so-called fibrohistiocytic tumors, pericytic tumors, and vascular lesions. We also outline the imaging features of masses encountered in the hand and wrist.
\end{abstract}

Soft tissue masses in the hand and wrist are frequently encountered in clinical practice. These may be classified as pseudotumors, benign neoplasms, or malignant neoplasms. The true ratio of benign to malignant lesions is difficult to determine due to differing inclusion criteria in various studies, but in practice the vast majority of masses are benign. ${ }^{1,2}$

Masses occurring in the hand tend to present early because they are easily palpable and often visible. The location of the mass and its anatomical relations can suggest a specific diagnosis. ${ }^{3,4}$ For example, glomus tumors typically occur in the fingertips or nail bed, and Dupuytren's contractures occur in the palm and often result in tethering of the adjacent flexor tendon.

Imaging has a crucial role in the evaluation of hand masses, helping narrow the differential and guide management. This article outlines the imaging features of soft tissue masses in the hand and wrist.

\section{Imaging Modalities}

Radiographs are often the initial imaging test and can show bony involvement or soft tissue mineralization, but the lesion

may not be seen. Computed tomography (CT) allows better delineation of the location and surrounding structures, but soft tissue characterization is limited.

Ultrasound (US), with its multiplanar capability, is very useful in determining the exact site and size of the hand masses, and it allows differentiation of cystic from solid lesions. ${ }^{5,6}$ Ongoing developments in US technology enable the depiction of submillimeter structures with unrivaled resolution. The use of extended field-of-view imaging allows a better appreciation of adjacent structures and improves image presentation. In addition, Doppler enables real-time functional evaluation of vascularity. US can also be used to guide biopsy. The main disadvantages of US are that it is highly operator dependent, bone is poorly evaluated, and soft tissue characterization is limited.

Magnetic resonance imaging (MRI) has the advantage of allowing tissue characterization. ${ }^{3,7,8}$ Several technical factors need to be considered for optimal imaging, such as patient positioning, the use of dedicated coils, and sequence selection. In general, an extremity-dedicated coil should be used to obtain high-resolution images with thin sections $(2-4 \mathrm{~mm})$ and a small field of view. Patients are usually scanned lying supine

(C) 2021. Thieme. All rights reserved. Thieme Medical Publishers, Inc., 333 Seventh Avenue, 18th Floor, New York, NY 10001, USA
DOI https://doi.org/ 10.1055/s-0041-1724017. ISSN 1089-7860. 
with arm by their side because this is the most comfortable position. They can also be scanned in the so-called superman position, lying prone with their hand above their head. Skin markers should be positioned to help localize the lesion. Images should ideally be obtained in all three orthogonal planes with a combination of T1-weighted and fluid-sensitive (short tau inversion recovery, proton-density fat-saturated, or T2-weighted fat-saturated) sequences. A gradient-echo sequence is useful if there is a suspected tenosynovial giant cell tumor because hemosiderin deposition within the lesion becomes more conspicuous. Intravenous (IV) gadolinium contrast can help distinguish between cystic and solid lesions, and determine the vascularity of lesions.

The ability of MRI to distinguish between benign and malignant soft tissue masses remains controversial. If soft tissue tumors are large $(>5 \mathrm{~cm}$ ) and deep, they are generally more likely to be malignant. However, malignant tumors in the hand may be small and superficial. ${ }^{9}$ Specific features that indicate malignancy include fascial edema, skin thickening, skin contact, hemorrhage, and necrosis. ${ }^{9}$ Other features include lobulation and peritumoral edema. In the hand, many soft tissue masses have characteristics that enable a specific diagnosis, due to a combination of signal characteristics, morphology, and location. ${ }^{3}$

Histologic analysis ultimately may be necessary to achieve a definitive diagnosis. Recent years have seen significant advances in the histologic diagnosis of soft tissue tumors and their classifications, particularly using immunohistochemistry. The use of antibody and antigen analysis, along with cytogenetics, are reflected in the latest World Health Organization classification of soft tissue tumors. ${ }^{10}$ The most accurate diagnosis is achieved when the clinical examination, imaging findings, and histopathology are combined in a multidisciplinary setting.

\section{Pseudotumors}

\section{Ganglion Cysts}

Ganglion cysts are the most common cause of a lump in the wrist. Their etiology remains obscure, but trauma is likely implicated. ${ }^{11}$ About $70 \%$ of ganglion cysts arise dorsally from the region of the scapholunate ligament or adjacent tissues, and they communicate with the joint via a pedicle. ${ }^{12,13}$ Up to $20 \%$ arise from the volar aspect of the wrist, with pedicles arising from the radioscaphoid, scaphotrapezial, or carpometacarpal joint. The volar ganglion typically is found between the radial artery and the flexor carpi radialis tendon. ${ }^{13}$ Approximately $10 \%$ arise from the region of the flexor tendon sheath. Ganglion cysts may also arise from the dorsal aspect of the distal interphalangeal joint in the context of osteoarthritis, so-called mucous cysts.

Ganglion cysts are most common in those aged 20 to 40 , with women affected more than men. Patients usually present with a mass. Restriction of movement or pain may be present. Nerve entrapment may occur, such as when a ganglion cyst lies within Guyon's canal and compresses the ulnar nerve. Clinically, a ganglion may feel like a firm mass tethered in place to the underlying joint capsule or tendon sheath. The cyst may transilluminate. In many circumstances the clinical findings are typical and imaging may not be required.

Histologically, ganglion cysts typically communicate with the joint via a tortuous pedicle. ${ }^{11}$ Ganglion cysts are differentiated from arthro-synovial cysts in that they do not have a true synovial lining on histology. On arthrography, communication between the radiocarpal joint and ganglion has been shown in $44 \%$ of patients with a dorsal wrist ganglion and in $85 \%$ with volar ganglion cysts. ${ }^{14}$ Contrast injected into ganglion cysts is not seen to enter the joint, indicating there is a one-way valve mechanism.

On US, a ganglion cyst appears as an anechoic or hypoechoic thin-walled, rounded oval or lobular mass with posterior acoustic enhancement. ${ }^{15}$ On Doppler interrogation there is no internal flow. These cysts are usually noncompressible, unlike a joint effusion or bursa. Complex ganglion cysts may have internal septations and be thick walled. ${ }^{13}$ Internal echogenic foci may also be present in small ganglion cysts. ${ }^{12} \mathrm{~A}$ connection with the underlying joint should be sought because this may require excision to avoid recurrence ( - Fig. 1).

On MRI, a ganglion cyst appears as a fluid signal mass, with minimal or no capsular enhancement. ${ }^{16}$ It may be

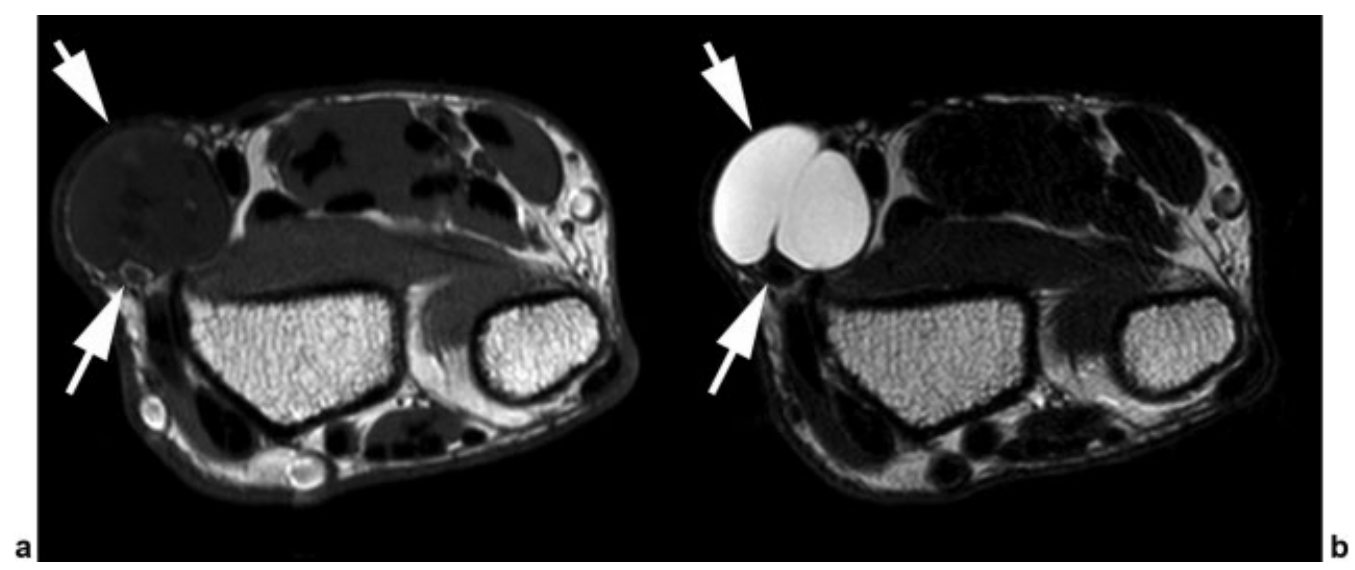

Fig. 1 Volar radial ganglion (a) Axial T1-weighted image demonstrating a well-circumscribed intermediate/low signal mass (short arrow) intimately related to the radial artery (longer arrow). (b) Axial T2-weighted image demonstrating a fluid signal loculated mass (short arrow) intimately related to the radial artery (longer arrow). 
unilocular or multilocular with thin septations, usually lying adjacent to a joint or tendon sheath. If high proteinaceous content or hemorrhage is present, it may appear iso- or hyperintense on T1-weighted images. MRI may be unable to differentiate between solid and cystic masses with certainty unless IV contrast is administered.

\section{Accessory Muscles}

Accessory muscles are congenital variations that may simulate a tumor. In the hand and wrist, the accessory palmaris longus, extensor digitorum brevis, extensor indicis proprius, flexor digitorum, and abductor pollicis minimi muscles are the most commonly encountered variants. ${ }^{17,18}$ In most cases, they are asymptomatic and discovered incidentally on imaging or at surgery. They present as a painless mass or with symptoms of nerve entrapment. An accessory abductor digiti minimi muscle, for example, may result in compression of the ulnar nerve in Guyon's canal, and an accessory palmaris longus may compress the median nerve in the carpal tunnel. $^{18}$

On imaging, accessory muscles are often overlooked. On US, the findings are of a mass that has the features of muscle, with a striated hypoechoic appearance, similar to adjacent muscles. On dynamic scanning with muscle contraction, the mass may alter in shape. ${ }^{17}$ Examination of the contralateral side may be useful for comparison purposes. On MRI, they appear isointense to normal muscle on all sequences and are most readily identified on $\mathrm{T} 1$-weighted images ${ }^{17}$ and often missed on fluid-sensitive sequences. An awareness and knowledge of muscle variants is ultimately the key to making the diagnosis (-Fig. 2 ).

\section{Foreign Body Granulomas}

Foreign body granulomas are formed by inflammation and reactive granulation tissue surrounding a foreign body. Their morphology varies according to the foreign body, its size and site. If a synovial sheath or joint is penetrated, there may be a florid synovial inflammatory reaction. ${ }^{19}$ Radiographs are a good screening technique and can demonstrate radio-opaque foreign bodies such as glass, metal, and bone. ${ }^{20}$ US is an excellent modality for evaluating foreign bodies. ${ }^{5,21}$ Most appear as hyperechoic structures with posterior acoustic shadowing. Thorns or splinters have a linear configuration. Foreign body granulomas have the appearance of a halo or mass-like low echogenicity surrounding a foreign body. There

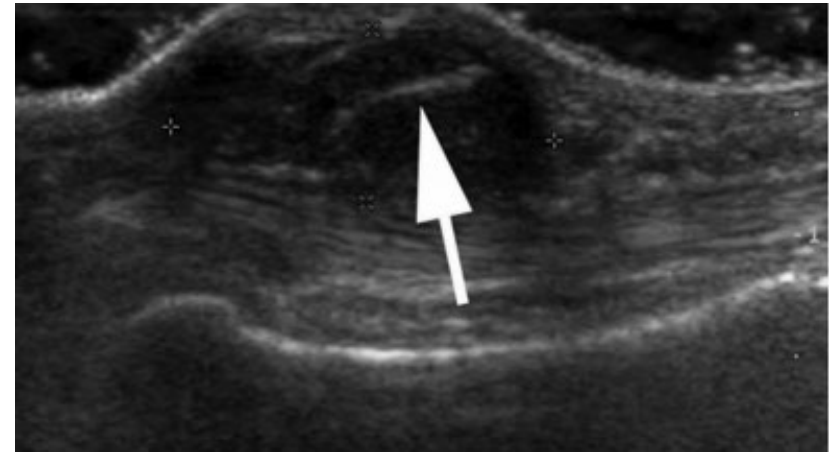

Fig. 3 Foreign body granuloma. Longitudinal ultrasound demonstrates a low echogenicity ovoid mass with a central linear echogenic foreign body (arrow), lying superficial to the flexor tendon at the level of the proximal phalanx.

is typically increased vascularity on Doppler interrogation. Abscesses appear as heterogeneous ill-defined fluid collections, with peripheral hypervascularity. On MRI, a foreign body granuloma has the appearance of an ill-defined mass of high $\mathrm{T} 2$ and intermediate/low T1 signal. ${ }^{22}$ The foreign body itself may be difficult to appreciate and typically appears as a central linear lesion of low T2 signal. Following gadolinium, there is peripheral ring-like enhancement of the granulation tissue (-Fig. $\mathbf{3}$ ).

\section{Tenosynovitis}

Tenosynovitis may be a manifestation of overuse, inflammatory arthritis, crystal disease, or infection. The clinical presentation may be of a mass or diffuse swelling. On US and MRI, there is fluid distension of the sheath with synovial hypertrophy. There may be increased vascularity on Doppler evaluation. On MRI, there is contrast enhancement of the inflamed synovium.

\section{Epidermal Cysts}

Epidermal cysts are also known as epidermoid or infundibular cysts. $^{23}$ They arise from a proliferation of epidermal cells within the dermis and are usually located in the subcutaneous tissue, typically with a small punctum. They are often posttraumatic or caused by a blockage of the pilosebaceous unit. Human papillomavirus has been implicated in palmoplantar epidermal cysts. Rarely they may be intraosseous, particularly at the fingertips. Cortical destruction may mimic a malignant or infectious process. The cyst contains keratin and cholesterol rather than fluid. If the wall ruptures, there may be a foreign

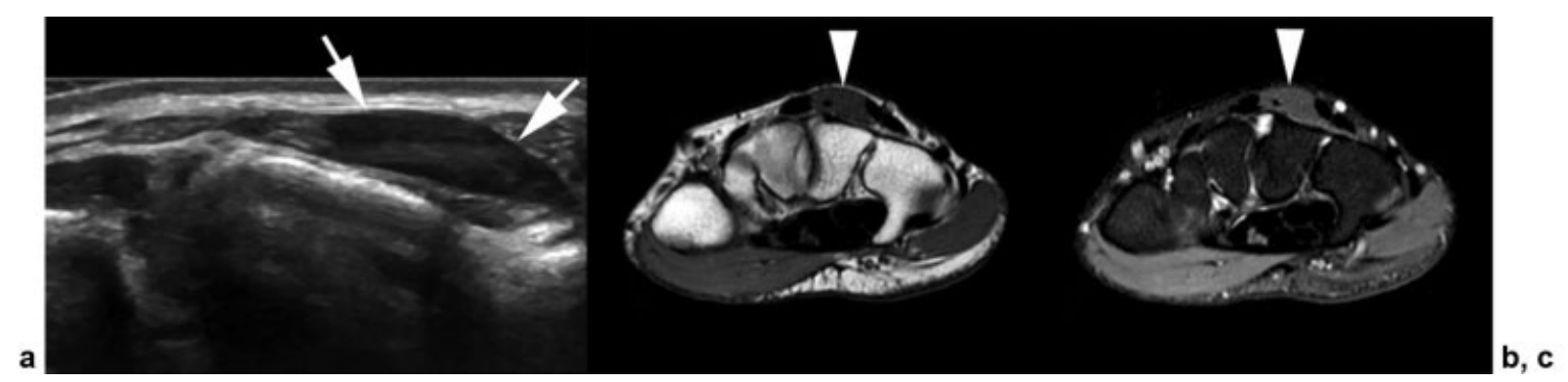

Fig. 2 Accessory extensor digitorum manus. (a) Transverse ultrasound demonstrates a fusiform low echogenicity lesion intimately related to the extensor digitorum tendons (arrows). (b) Axial T1-weighted image demonstrating a well-defined lesion that is isointense to other muscles (arrowhead). (c) Axial proton-density fat-saturated image demonstrating an inconspicuous lesion that is isointense to other muscles (arrowhead). 
body reaction..$^{23}$ Secondary infections may occur with abscess formation.

On US, the lesion is usually well defined with variable echogenicity depending on the nature of its contents. ${ }^{23}$ These lesions are typically hypoechoic with posterior acoustic enhancement. The cyst may contain hyperechoic debris or clusters of keratin. The "pseudo-testis sign" refers to an intralesional texture that appears similar to a testis, with bright echogenic reflectors and filiform anechoic areas. Associated features include dermal attachment and focal dermal protrusion. The size and shape are variable, ranging from a simple ovoid configuration to a lobulated appearance. On Doppler, there is no internal flow, but if there is cyst rupture there may be pericystic changes with increased vascularity.

On MRI, the appearance depends on the cyst contents. Usually they are of high T2 and low T1 signal, mimicking fluid. ${ }^{24}$ Lesions with a high lipid content demonstrate high signal on both $\mathrm{T} 1$ - and $\mathrm{T} 2$-weighted sequences. If there is a high keratin content or microcalcifications, low T2 signal may be observed. Following IV gadolinium, there may be enhancement of the cyst wall but not of the contents. With rupture, septae may occur, and there may be a thickened rim with "fuzzy" peripheral enhancement. The imaging features can simulate an infectious or neoplastic mass (-Fig. 4).

\section{Gout}

Gout is the most common form of inflammatory arthritis and characterized by hyperuricemia with the formation of monosodium urate (MSU) crystals that result in recurrent episodes of inflammation. ${ }^{25}$ Men are more affected than women, and incidence increases with age. Gouty tophi consist of a fibrovascular matrix with a core of MSU crystals, lipids, and cellular debris, surrounded by granulation tissue. There is a predilection for the hands, feet, and elbows.

On radiographs, tophi have a round or oval appearance with relative increased attenuation compared with adjacent soft tissues. Periarticular erosions and secondary degenerative changes are typically present. The US findings can be divided into generic findings associated with inflammatory arthritis and those suggestive of gout, as defined by consensus by the Outcome Measures in Rheumatology Clinical Trials group. ${ }^{25}$ The generic findings include synovitis and effusions, with hyperemia on Doppler. Tophi have a nodular appearance with bright central echogenic crystals interspersed with hypoechoic fibrous septae. The surrounding granulation tissue appears as a hypoechoic halo around the lesion. Other US features of gout include the presence of erosions and the "double-contour sign," a curvilinear echogenic layer of crystals lying on the surface of the articular cartilage, parallel to the subchondral bone. Furthermore, micro-tophi may be evident as foci of increased echogenicity within joint effusions or within regions of synovial hypertrophy. A recent multicenter study found that US had a sensitivity of $76.9 \%$ and a specificity of $84.3 \%$ for detecting MSU crystal deposition using crystal analysis as the gold standard. 26

Dual-energy computed tomography (DECT) is a relatively novel tool to detect and quantify MSU crystal deposition. ${ }^{25}$ The ability to quantify tophus allows it to be used to monitor treatment response. The pooled sensitivity and specificity of DECT for the diagnosis of gout is estimated as $88 \%$ and $90 \%$, respectively. ${ }^{27}$ MRI has the ability to demonstrate synovitis, erosions, and tophi but has limited specificity compared with US and $\mathrm{DECT}^{25}$ (-Fig. 5).

\section{Rheumatoid Nodules}

Rheumatoid nodules are small firm inflammatory subcutaneous lumps that occur in up to $20 \%$ of patients with rheumatoid arthritis or rheumatic diseases such as systemic lupus erythematosus. ${ }^{28}$ Affected patients are almost invariably rheumatoid factor and anti-cyclic citrullinated peptide positive, with long-standing disease, and they are more prone to extra-articular features. Rheumatoid arthritis patients treated with methotrexate may develop micronodules that are typically smaller and develop more rapidly than classic rheumatoid nodules. ${ }^{29}$ Rheumatoid nodules tend to occur over joints that are subject to repetitive trauma such as

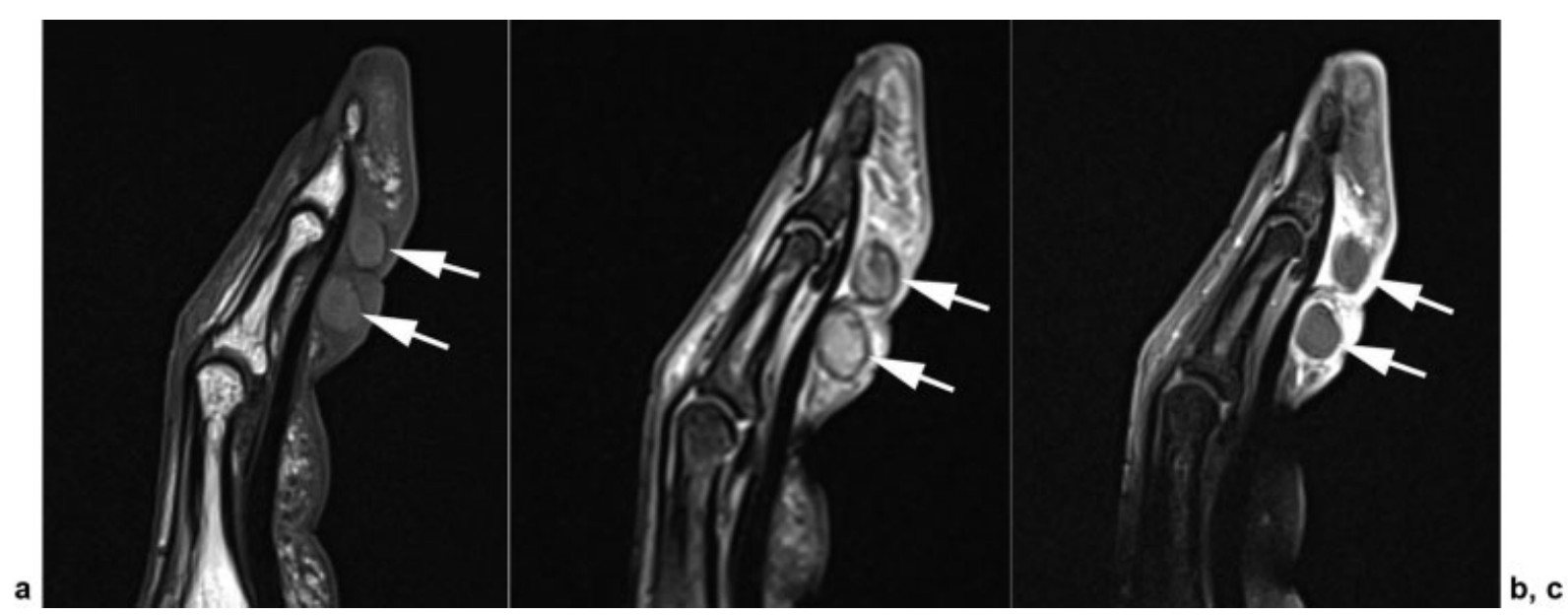

Fig. 4 Epidermal cyst with partial rupture. (a) Sagittal T1-weighted image demonstrating a bilobed lesion in the subcutaneous tissues that is slightly hyperintense (arrows). (b) Sagittal proton-density fat-saturated image demonstrating heterogeneous intermediate signal within the lesion (arrows) with surrounding soft tissue inflammation suggesting cyst leakage. (c) Sagittal T1 fat-saturated image following intravenous gadolinium shows no enhancement (arrows) indicating cystic contents. 


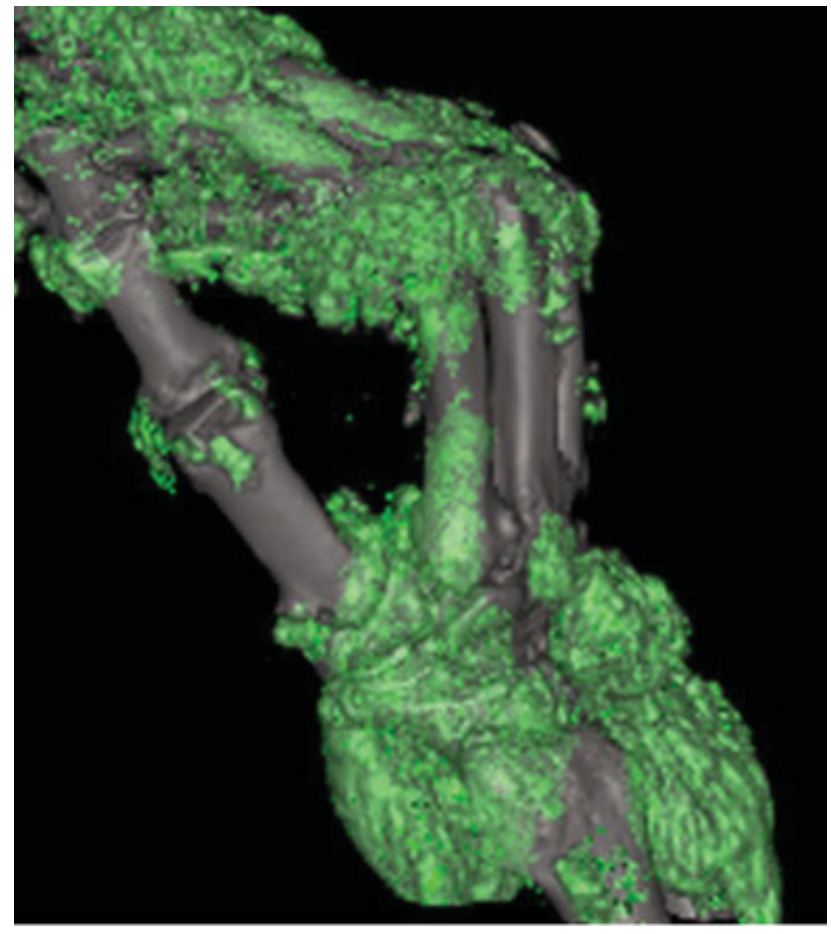

Fig. 5 Gout. Dual-energy computed tomography demonstrates multiple large soft tissue masses in the hand encoded in green.

the dorsum of the fingers, toes, and elbows. Bursae, joints, and tendons may also be involved. Occasionally they may occur in the lungs. In the hand, they are usually nontender, but they can be painful and may ulcerate. Histologically, the lesion consists of chronic inflammatory cells that may be accompanied by central necrosis.

On imaging, the diagnosis is usually suggested by the presence of underlying rheumatoid changes in the joints such as erosions and synovitis. On US, rheumatoid nodules are relatively nonspecific and may have a homoge- neous hypoechoic appearance. ${ }^{30}$ A central discrete hypoechoic area may indicate central necrosis or cyst formation. On Doppler, there may be increased vascularity. On MRI, lesions may be iso- or hypointense to muscle on T1-weighted images. On fluid-sensitive sequences, they are typically of increased T2 signal and may demonstrate a necrotic or cystic component. ${ }^{28}$ Solid lesions may enhance uniformly, whereas lesions with a necrotic or cystic component enhance peripherally.

\section{Neoplasms}

\section{Fibrohistiocytic Tumors}

So-called fibrohistiocytic tumors are composed of a diverse group of reactive and neoplastic lesions including xanthomas, fibrous histiocytomas, and tenosynovial giant cell tumors (-Table 1). ${ }^{31}$ They are categorized according to their malignant potential into benign and intermediate fibrohistiocytic lesions. In the hand, by far the most common fibrohistiocytic tumors are tenosynovial giant cell tumors.

\section{Tenosynovial Giant Cell Tumors}

The term tenosynovial giant cell tumor (TSGCT) replaces the numerous names that were in use including giant cell tumor of the tendon sheath, localized nodular tenosynovitis, xanthoma, and pigmented villonodular synovitis. TSGCTs are the most common solid masses to occur in the hand. They are divided into localized and diffuse types. ${ }^{32}$ Patients typically present between the ages of 20 and 50 years, with a firm immobile lump, with women more affected. Most localized TSGCTs occur in the hands and feet, outside of the joints, in close relation to the tendon sheath or joint capsule. Localized TSGCTs are typically solitary, but multifocal cases have been reported. In the hand, up to $85 \%$ of cases occur in the fingers, with the flexor tendon sheaths more often involved than the extensor sheaths. Most cases of diffuse TSGCT occur in larger joints such as the knee, ankle,

Table 1 Selected soft tissue tumors of the hand according to tissue origin ${ }^{31}$

\begin{tabular}{|l|l|l|l|l|}
\hline Tissue & Benign & $\begin{array}{l}\text { Intermediate } \\
\text { (locally aggressive) }\end{array}$ & $\begin{array}{l}\text { Intermediate } \\
\text { (rarely metastasizing) }\end{array}$ & Malignant \\
\hline $\begin{array}{l}\text { So-called } \\
\text { fibrohistiocytic }\end{array}$ & TSGCT & & & Malignant TSGCT \\
\hline $\begin{array}{l}\text { Adipocytic/ } \\
\text { Lipomatous }\end{array}$ & $\begin{array}{l}\text { Lipoma } \\
\text { Fibrolipomatous } \\
\text { hamartoma }\end{array}$ & Atypical lipomatous tumor & & Liposarcoma \\
\hline $\begin{array}{l}\text { Fibroblastic/ } \\
\text { Myofibroblastic }\end{array}$ & Nodular fasciitis & Palmar fibromatosis & & Myxofibrosarcoma \\
\hline $\begin{array}{l}\text { Peripheral nerve } \\
\text { neurofibroma }\end{array}$ & $\begin{array}{l}\text { Schwannoma, } \\
\text { Hemangioma }\end{array}$ & & & MPNST \\
\hline $\begin{array}{l}\text { Pericytic/ } \\
\text { Perivascular }\end{array}$ & & & & Angiosarcoma \\
\hline Skeletal muscle & & & & Rhabdomyosarcoma \\
\hline Uncertain origin & & & & $\begin{array}{l}\text { Synovial sarcoma, } \\
\text { epithelioid sarcoma }\end{array}$ \\
\hline
\end{tabular}

Abbreviations: MPNST, malignant peripheral nerve sheath tumor; TSGCT, tenosynovial giant cell tumor. 


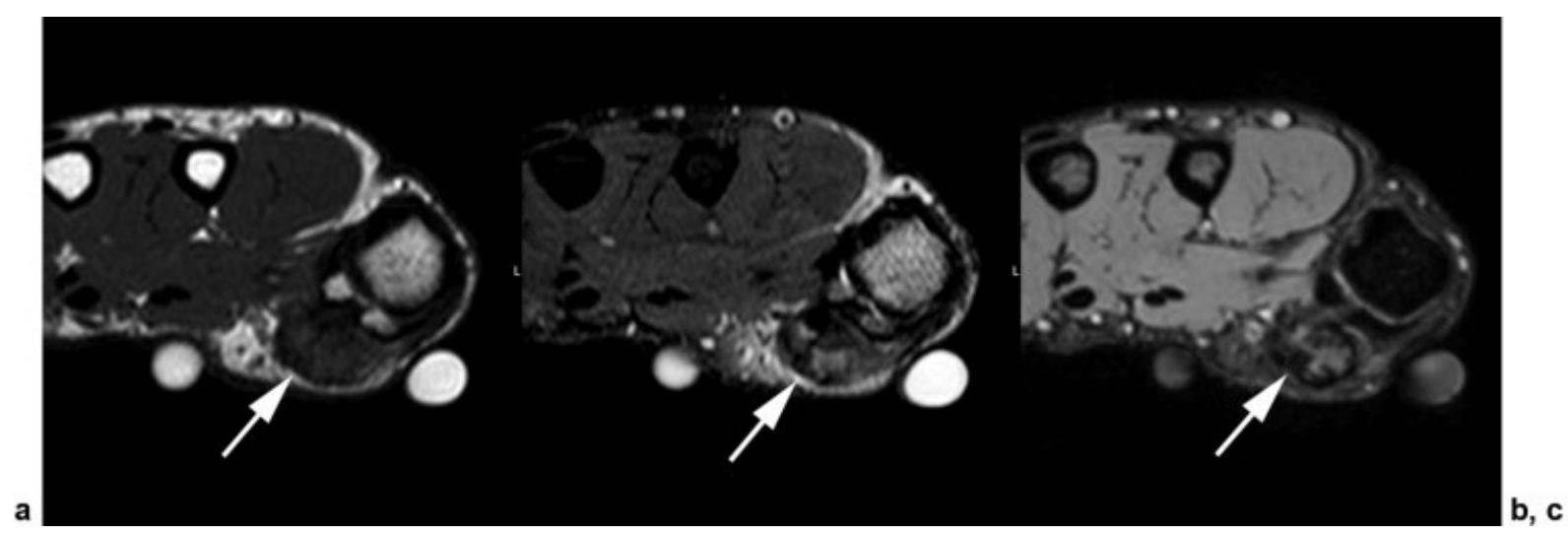

Fig. 6 Tenosynovial giant cell tumor. (a) T1-weighted image demonstrating an intermediate/low signal heterogeneous mass (arrow) intimately related to the flexor pollicis longus tendon. (b) Proton-density fat-saturated image demonstrating a heterogeneous low signal lesion (arrow). (c) Gradient-echo image demonstrating areas of very low signal indicating the presence of hemosiderin (arrow).

and hip, but the wrist can be affected. Rarely there may be malignant transformation of TSGCT that may be locally destructive and can metastasize.

Histologically, there is synovial hypertrophy with a mononuclear histiocytic reaction, with scattered giant cells, a rich vascular plexus, and local hemosiderin deposition. ${ }^{32}$ The degree of hemosiderin staining tends to be greater in diffuse disease. Using immunohistochemistry, TSGCT overexpresses colony-stimulating factor 1 .

On radiographs, erosions, soft tissue calcifications, and periosteal reactions may rarely be seen. On US, localized TSGCT appears as a hypoechoic lobulated mass of homogeneous or heterogeneous texture. ${ }^{33}$ The lesion is intimately related to or tethered to the tendon sheath and does not usually move with the tendon on dynamic evaluation. Localized TSGCT usually has well-defined boundaries but may adhere to or invade surrounding tissues. There is usually vascularity on Doppler. On MRI, localized TSGCT characteristically appears as a lobulated mass of low T1 and intermediate to low $\mathrm{T} 2$ signal, reflecting the presence of hemosiderin. ${ }^{32}$ often the appearances are heterogeneous. Gradient-echo sequences are useful to demonstrate the presence of hemosiderin. Localized TSGCTs do not typically result in macroscopic hemorrhage, so unlike diffuse TSGCT they do not have the same degree of blooming artifact on gradient-echo sequences ( - Figs. $\mathbf{6}$ and $\mathbf{7}$ ).

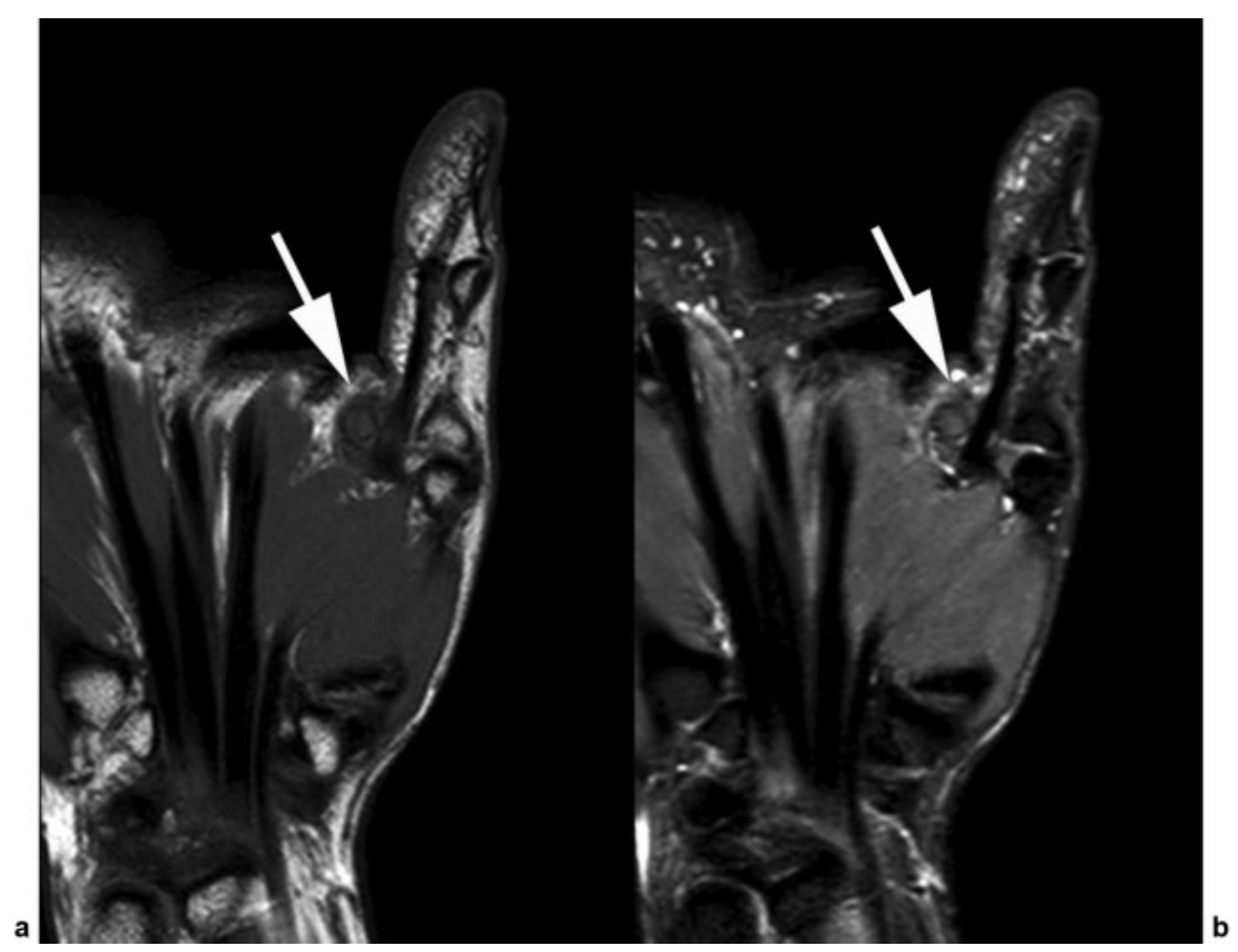

Fig. 7 Tenosynovial giant cell tumor. (a) Coronal T1-weighted image demonstrating a lobulated heterogeneous low signal mass adjacent to the flexor pollicis longus tendon (arrow). (b) Coronal short tau inversion recovery image demonstrating a low signal mass (arrow). 


\section{Adipocytic/Lipomatous Tumors}

Lipomatous tumors are mesenchymal neoplasms that have lipogenic differentiation. ${ }^{31}$ They are classified as lipomas, atypical lipomatous tumors, and liposarcomas. Lipoma variants such as angiolipoma and myolipoma contain nonadipose components. Although they are the most common soft tissue tumor in the body, lipomatous tumors involving the hand are uncommon. ${ }^{34}$ Hand lipomas may be found in any soft tissue plane but are typically located in the thenar eminence or mid-palm. Clinically, most present as painless slow-growing mobile soft tissue lumps.

US has been shown to be a useful tool in the diagnosis of superficial lipomas with good overall sensitivity (85.7\%) and high specificity (95.9\%). ${ }^{35}$ About $59 \%$ of lipomas have been found to be isoechoic to adjacent fat, with $24 \%$ hyperechoic and $17 \%$ hypoechoic. Most cases show absent (59\%) or minimal (41\%) color flow on Doppler interrogation. They appear as lobular masses with hyperechoic linear interfaces, but some superficial lipomas may not appear as discrete lesions. The presence of nonlipomatous contents, nodularity, or septations suggests a liposarcoma or lipoma variant. However, lipomas may contain nonadipose components due to fat necrosis, calcification, fibrosis, inflammation, and myxoid degeneration.

On MRI, lipomas demonstrate signal similar to subcutaneous fat on all sequences and should be of homogeneously low signal on fat-suppressed sequences. ${ }^{36}$ As with US, a deep location and nonlipomatous contents raise the possibility of an atypical lipomatous tumor or liposarcoma (-Fig. 8).

\section{Fibrolipomatous Hamartomas}

Fibrolipomatous hamartomas are classified as adipocytic tumors. ${ }^{31}$ They are also called lipomatous hamartomas, fibrofatty overgrowths, neural fibrolipomas, perineural lipomas, and intraneural lipomas. ${ }^{37}$ They are rare benign congenital tumors most commonly found in the median nerve, at the level of the wrist or hand. Other sites include the radial, ulnar, sciatic, and plantar nerves. ${ }^{37}$ They are present at birth, and their natural history is to increase gradually in size, presenting as a mass or symptoms of a compressive neuropathy. There may be enlargement of a digit with bony and fatty overgrowth, known as macrodystrophia lipomatosa, in up to two thirds of cases. ${ }^{38}$ Histologically, dense fibrofatty tissue infiltrates the endoneurium, perineurium, and epineurium. ${ }^{37}$

On US, there is a cable-like appearance with alternating hyperechoic and hypoechoic bands that are due to fibrofatty tissue and neural tissue, respectively. ${ }^{39}$ On MRI, thickened serpiginous nerve bundles are present with surrounding fatty tissue that returns high T1 signal, giving a "spaghetti sign." ${ }^{40}$ On axial images, the findings are reminiscent of a cut electrical cable, showing the "coaxial cable sign." The degree of fatty and fibrous tissue infiltration can be variable, leading

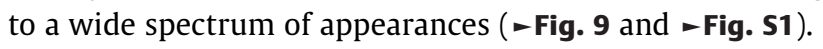

\section{Fibroblastic Tumors}

Fibroblastic and myofibroblastic tumors encompass a large subset of soft tissue tumors, divided into four main groups: benign, intermediate (locally aggressive), intermediate (rarely metastasizing), and malignant. ${ }^{10}$ Histologically, many fibroblastic/myofibroblastic lesions are moderately or highly cellular, and they may be mistaken for sarcomas. In the hand and wrist, the most commonly encountered lesions are the fibroma of the tendon sheath and superficial fibromatosis (Dupuytren's contracture) that are both in the benign group.

\section{Fibroma of the Tendon Sheath}

Fibroma of the tendon sheath (FTS) is a benign slow-growing benign fibroblastic nodular tumor arising from the synovial sheath with a predilection for the palm and flexor aspect of the digits, often in relation to the annular pulleys. ${ }^{41}$ Intra-articular tumors may also occur at the wrist. The clinical and imaging features of FTS may resemble TSGCT. Both types of tumor are intimately related to tendons and present as painless slowgrowing masses, typically in patients aged 20 to 50 years. Men are affected more than women. Histologically, FTS is composed of spindle-shaped cells similar to fibroblasts in a densely collagenous stroma with slit-like spaces. Some lesions may have increased cellularity peripherally, resembling nodular fasciitis. $^{42}$

On US, FTS appears as a well-circumscribed hypoechoic mass closely related to a tendon with internal heterogeneity and increased vascularity on Doppler. ${ }^{43}$

On MRI, FTS appears as a well-defined soft tissue mass with nonuniform low signal intensity on T1- and

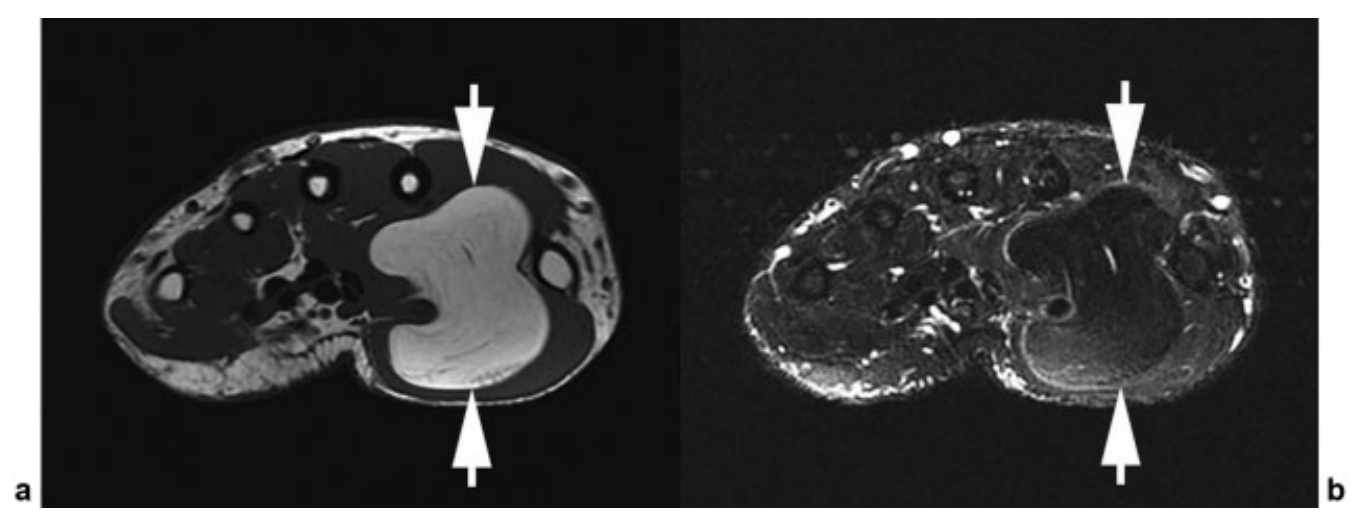

Fig. 8 Atypical lipoma. (a) Axial T1-weighted image demonstrating an intramuscular high T1 signal mass (arrows) in the thenar eminence consistent with a lipomatous tumor. There are a few internal striations. (b) Axial proton-density fat-saturated image demonstrating a homogeneous low signal mass (arrows) with a single coursing vessel. 


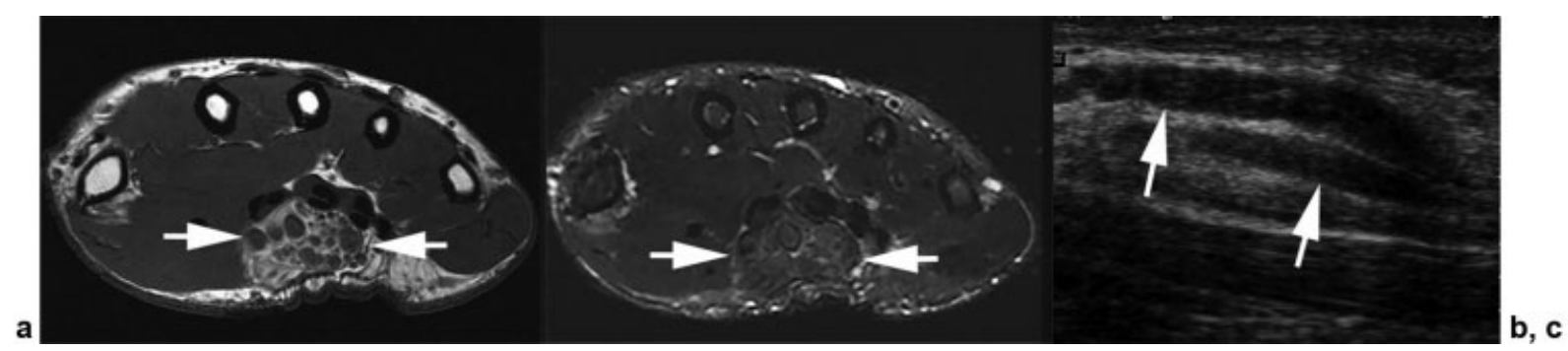

Fig. 9 Fibrolipomatous hamartoma. (a) Axial T1-weighted image demonstrating a mass in the carpal tunnel (arrows) containing multiple rounded structures in a fatty matrix, representing the "coaxial cable sign." (b) Axial proton-density fat-saturated image demonstrating a low signal mass and the presence of lipomatous tissue (arrows). (c) Longitudinal ultrasound demonstrating tubular structures in the carpal tunnel (arrows), representing the "spaghetti sign."

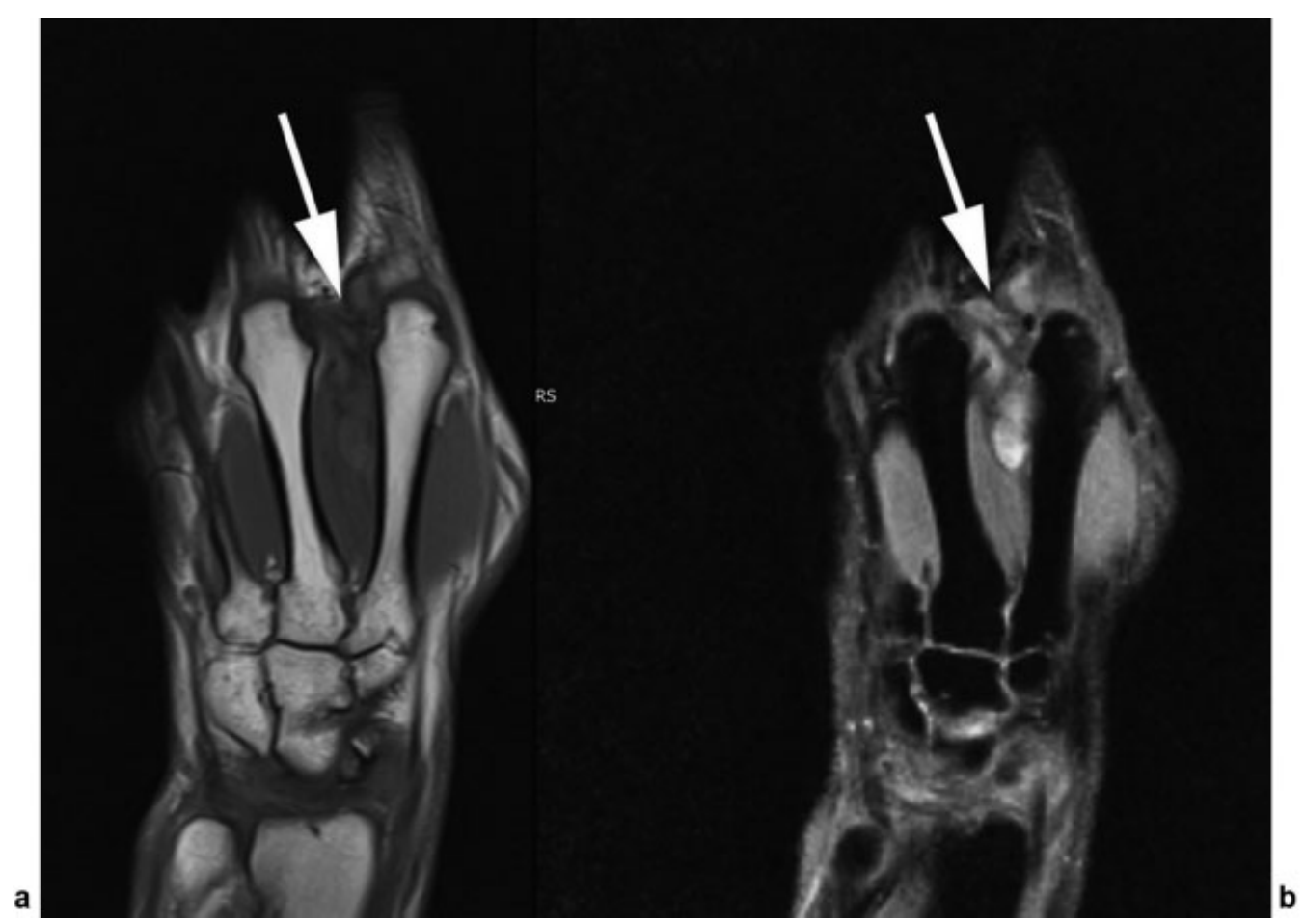

Fig. 10 Fibroma of the tendon sheath. (a) Coronal T1-weighted image demonstrating an ill-defined lesion between the index and middle metacarpals with areas of very low T1 signal suggesting a fibrous component (arrow). (b) Coronal proton-density fat-saturated image demonstrating a heterogeneous lesion with low T2 signal components (arrow).

T2-weighted sequences. ${ }^{44}$ On fluid-sensitive sequences, the low signal patterns within the lesion are typically stripe-like or irregular, compared with TSGCTs that have a more granular appearance. If increased cellularity or myxoid change are present, these may result in high T2 signal intensity. Contrast enhancement is variable. There should be no blooming artifact on gradient-echo sequences because the lesions do not contain hemosiderin (- Fig. 10).

\section{Fibromatoses}

The fibromatoses are locally aggressive fibroblastic neoplasms that lack metastatic potential but tend to recur locally. ${ }^{10}$ They are classified into superficial and deep types. The superficial fibromatoses are composed of palmar (Dupuytren's contracture) and plantar fibromatosis, and Peyronie's disease. Up to $85 \%$ of deep fibromatoses have a $\beta$-catenin gene mutation on immunohistochemistry that is not found with superficial fibromatoses.
Dupuytren's contracture is a benign fibroproliferative disorder involving the palmar fascia, resulting in nodules that form cord-like attachments to the flexor tendons. ${ }^{45}$ Eventually flexion contractures may become debilitating. Multiple factors including increasing age, diabetes, alcoholism, epilepsy, manual labor, and trauma have been implicated. ${ }^{45}$

Imaging can confirm the diagnosis, evaluate disease activity, and help guide percutaneous treatment and assess response to treatment. ${ }^{45}$ On US, the superficial palmar aponeurosis overlies the flexor tendons and has a thin echogenic lamellar appearance. Dupuytren's contractures appear as nodules of low echogenicity, located between the superficial aspect of the flexor tendons and the dermis, typically at the level of the distal metacarpal shaft. ${ }^{46}$ Early nodules are hypoechoic compared with tendons and typically demonstrate increased vascularity, whereas older nodules are more hyperechoic and avascular. ${ }^{5}$ The fourth ray is most commonly affected (-Fig. 11). 

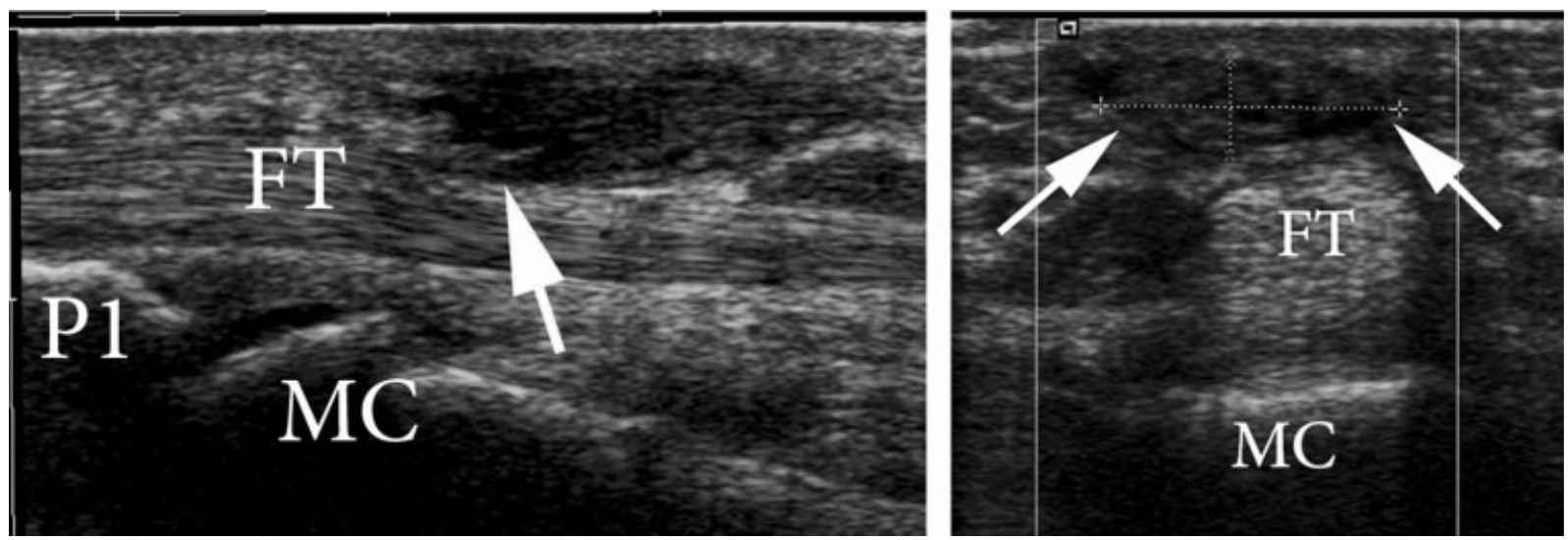

Fig. 11 Dupuytren's contracture. (a) Sagittal ultrasound (US) demonstrating the flexor tendon (FT), metacarpal (MC), and proximal phalanx (P1). There is a low echogenicity mass with a cord-like projection extending to the surface of the FT (arrow). (b) Axial US demonstrating the low signal mass in close relation to the FT.

On MRI, most nodules have an intermediate signal intensity on both T1- and T2-weighted images, similar to muscle, with stippled areas of low signal intensity. The cords typically have a uniformly low signal intensity similar to tendons on T1- and T2-weighted images. ${ }^{47}$ Lesions may be easier to detect on T1-weighted images than fluid-sensitive sequences because the lesion is more conspicuous when there is surrounding fat (-Fig. 12).

\section{Neural Tumors}

Peripheral nerve sheath tumors (PNSTs) may be benign or malignant. ${ }^{31}$ In the hand, benign tumors are composed of two major forms, schwannomas and neurofibromas, and a rare form, granular cell tumors. The malignant tumors are simply classified as malignant peripheral nerve sheath tumors (MPNSTs).

Schwannomas are typically solitary and occur sporadically in young to middle-aged adults, with no sex predilection. ${ }^{48}$ The histologic subtypes include common, plexiform, cellular and epithelioid types, and ancient schwannomas. Multiple schwannomas and the plexiform subtype are associated with neurofibromatosis type 1 (NF1). Schwannomas are generally well encapsulated and do not infiltrate the nerve fascicles, allowing complete surgical excision without injuring the corresponding nerve, unlike neurofibromas that are intertwined with the nerve fascicles.

The most common subtype of neurofibroma is a solitary localized neurofibroma that usually occurs in small nerves. Diffuse-type neurofibromas occur sporadically and are associated with NF1 in only $10 \%$ of cases, whereas plexiform neurofibromas are characteristic of NF1. ${ }^{48}$ They begin in childhood as nodular regions within affected nerves giving a "bag of worms" appearance. There is a predilection for nerves adjacent to the vertebral column with slow outward progression. Eventually large tumors may form with hypertrophy and deformity of a limb, resulting in elephantiasis neuromatosa (-Fig. 13).

On imaging, PNSTs appear as small hypoechoic spindleshaped nodules oriented along the axis of a peripheral nerve with distal tail-like formations at either end. ${ }^{48,49}$ Schwannomas typically displace the nerve fascicles and are encased by the

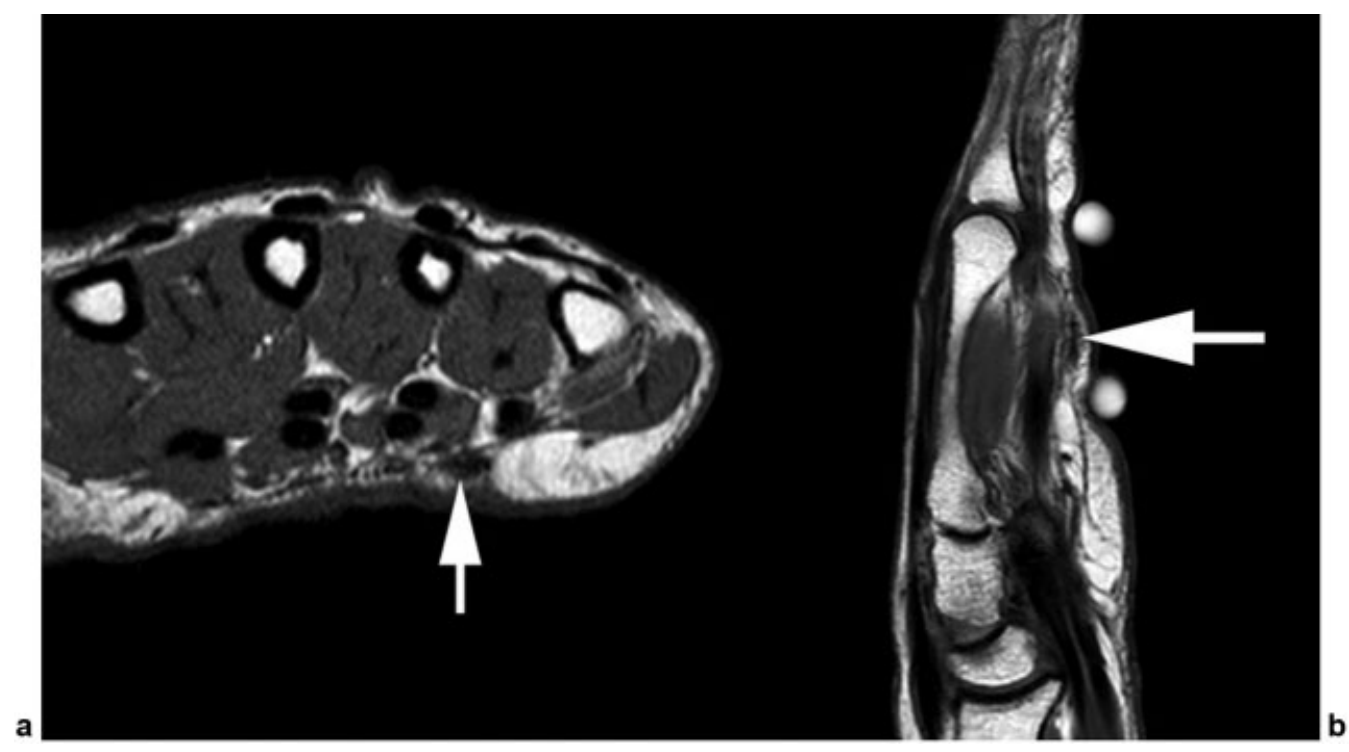

Fig. 12 Dupuytren's contracture. (a) Axial T1-weighted image demonstrating a small intermediate/low signal nodule (arrow) in continuity with the deep palmar fascia. (b) Sagittal T1-weighted image demonstrating a low signal nodule (arrow) at the level of the metacarpal shaft. 


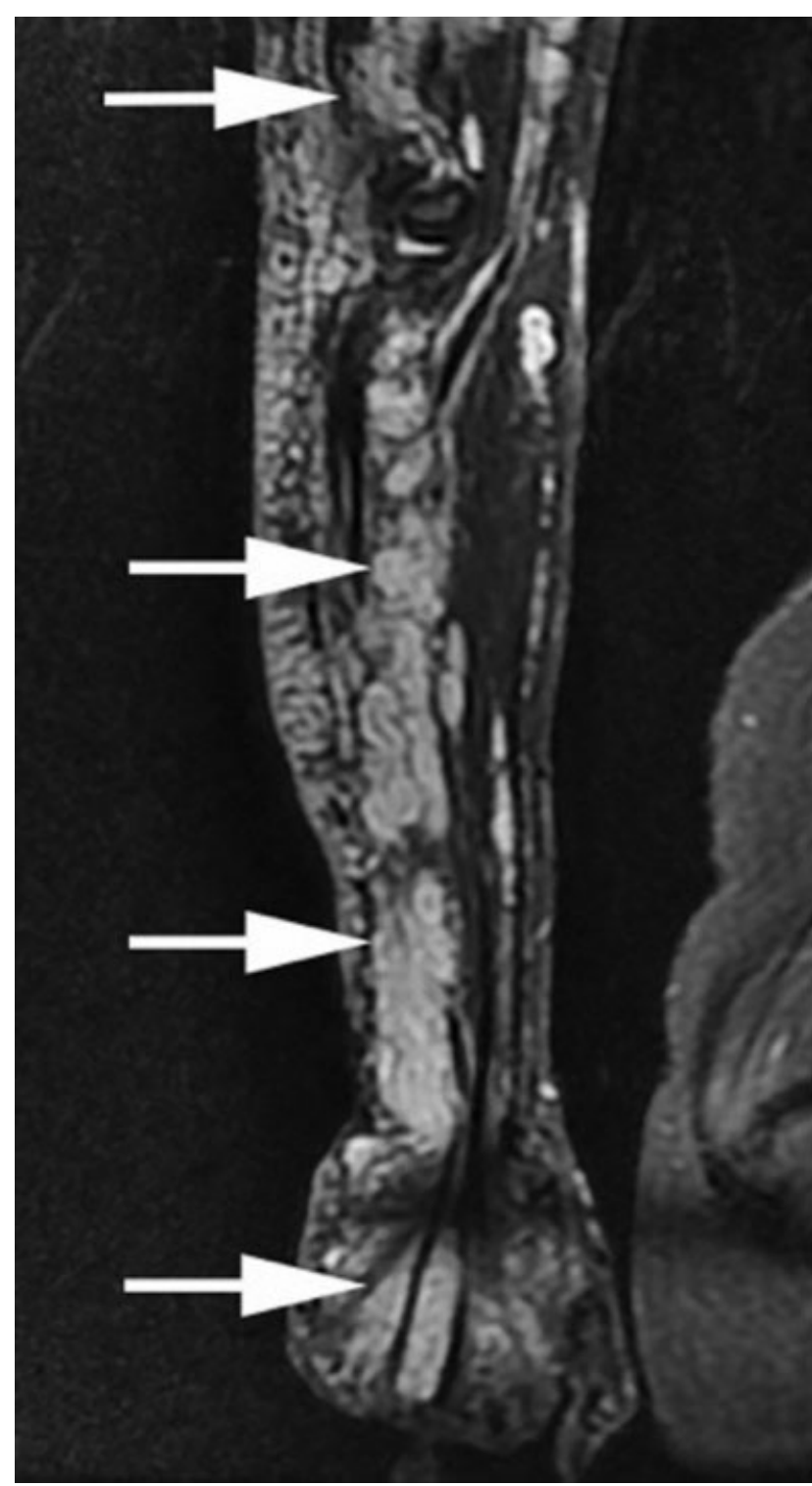

Fig. 13 Plexiform neurofibroma. Coronal magnetic resonance imaging of the forearm demonstrating an extensive plexiform neurofibroma of the forearm (arrows) with a "bag of worms" appearance.

nerve sheath, with the lesion positioned eccentrically in relation to the parent nerve. ${ }^{49}$ Neurofibromas, in contrast, are usually positioned centrally in relation to the parent nerve. However, differentiation on imaging may be difficult.

On US, PNSTs appear hypoechoic with variable posterior acoustic enhancement. ${ }^{50}$ Large lesions may have hyperechoic calcifications and contain degenerative cystic foci (-Fig. 13). Ancient schwannomas may have large areas of cystic change and may demonstrate hemorrhage and calcifications. Cystic schwannomas may be mistaken for ganglion cysts. On Doppler US, vessels may be seen entering from the proximal and distal pole with monomorphic duplex waveforms and a benign (hierarchic) vascular architecture. Localized neurofibromas are well-defined nodular lesions that arise from the parent nerve in a fusiform shape. There may be a hyperechoic central zone with a hypoechoic peripheral zone, showing a "ring sign" corresponding to a fibrocollagenous central region surrounded by myxoid matrix. ${ }^{51}$

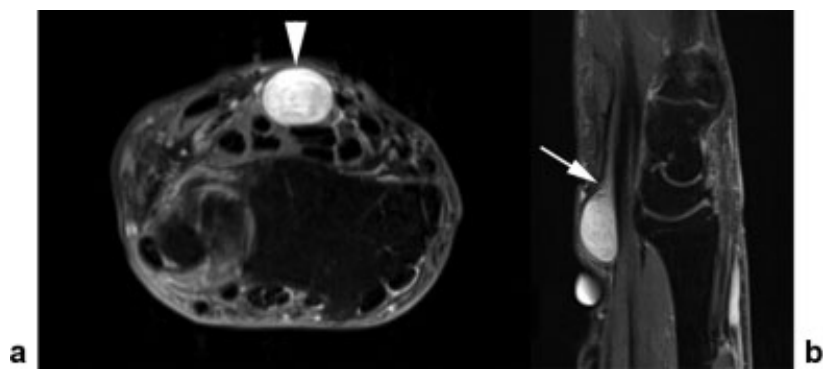

Fig. 14 Schwannoma of the median nerve. (a) Axial T2 fat-saturated image demonstrating an ovoid high signal mass in the carpal tunnel. (b) Sagittal proton-density fat-saturated image demonstrating a fusiform mass with a dural tail (arrow).

On MRI, PNSTs appear as fusiform masses of high T2 signal and intermediate or low T1 signal. A "target sign" with central low T2 signal corresponding to US findings may be seen. ${ }^{52}$ A rim of fat may be seen surrounding the tumor, particularly at the tapered ends of the lesion, suggesting the lesion originates in the intra- or intermuscular space, described as the "split fat sign." ${ }^{33}$ This occurs more commonly with benign slow-growing lesions. The "fascicular sign" manifests as multiple small ringlike structures with peripheral higher T2 signal intensity that are thought to correspond to the fascicular bundles seen pathologically in neurogenic neoplasms ${ }^{48}$ (-Figs. 14 and 15).

MPNSTs include all malignant tumors with neural differentiation that have arisen from peripheral nerves. Histologically, they are comprised of neural tissue that has undergone malignant transformation intermixed with varying amounts of non-neurogenic neoplastic tissue. ${ }^{48}$ They comprise 5 to $10 \%$ of all soft tissue tumors. Patients are typically aged 20 to 50 years. Malignant transformation may occur in 8 to 15\% of patients with plexiform neurofibromas in patients with NF1. ${ }^{54}$ MPNSTs often do not demonstrate a rim of fat due to their infiltrative margins. They predominantly occur in the brachial, sacral, and lumbar plexus regions, and are very rare in the hand. They characteristically grow rapidly and often result in sensory or motor deficits. Early MPNSTs appear as heterogeneous fusiform masses in relation to a peripheral nerve on imaging. There may be a pseudocapsule formed by a thickened irregular outer nerve sheath. Heterotopic mineralization or bone may be present. As the lesion grows, it becomes more irregular, and regions of necrosis or hemorrhage may occur, resulting in heterogeneous high T2 signal on MRI, with patchy enhancement following gadolinium. ${ }^{54} \mathrm{~A}$ combination of 18F-fluorodeoxyglucose positron emission tomography (PET) with CT (PET/CT) may be able to detect malignant transformation in patients with NF-1. ${ }^{55}$

\section{Vascular Anomalies}

The classification of vascular anomalies is complicated. Using a combination of clinical features, cellular turnover, and histologic findings, vascular anomalies have been broadly classified into vascular tumors and vascular malformations by the International Society for the Study of Vascular Anomalies. ${ }^{56}$ Despite progress in consensus nomenclature, the widespread use of incorrect terminology persists. Much of the literature 


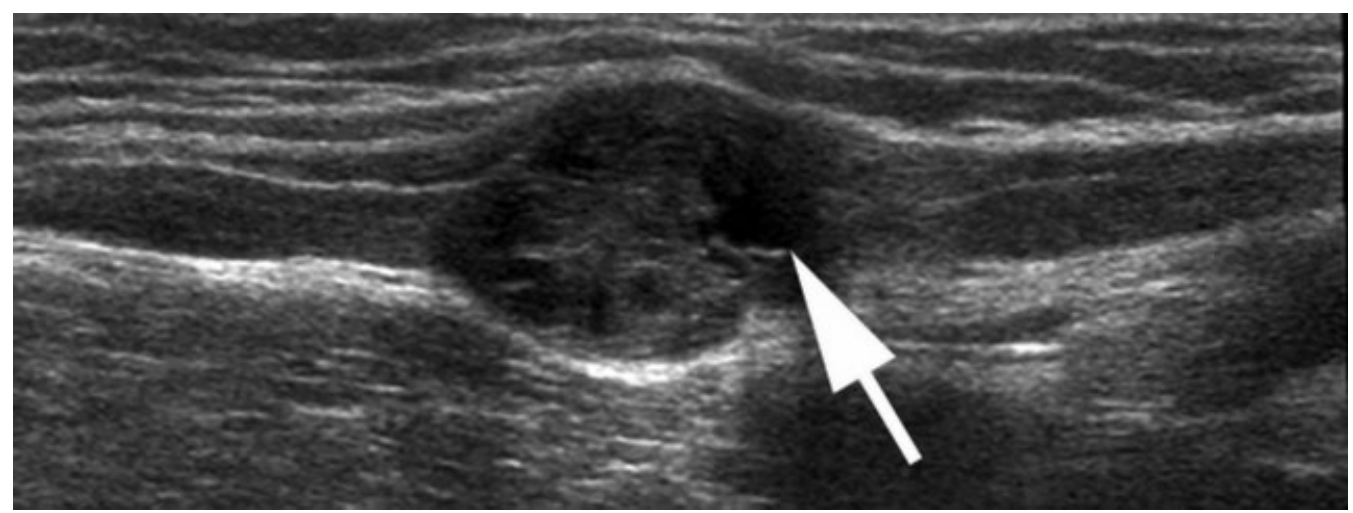

Fig. 15 Schwannoma. Longitudinal ultrasound demonstrating a fusiform eccentric mass seen in continuity with the ulnar nerve. There is cystic degeneration within the lesion (arrow).

regarding vascular anomalies does not clearly distinguish between these entities. In the hand, both vascular tumors and vascular malformations may be encountered.

\section{Vascular Tumors}

Vascular tumors are true neoplasms with increased endothelial cell turnover, classified by their malignant potential. ${ }^{57}$ Benign vascular tumors include infantile and congenital hemangiomas and pyogenic granulomas. Locally aggressive vascular tumors include tufted angiomas and kaposiform hemangioendotheliomas. Aggressive vascular tumors include angiosarcomas and epithelioid hemangioendotheliomas. In the hand, the most common vascular tumors are hemangiomas.

Hemangiomas are usually not evident at birth but quickly appear in the first month of life, followed by rapid growth in the first year and then spontaneous regression by 7 years. ${ }^{57}$ On US, hemangiomas are well-defined lesions that may be hyper- or isoechoic to adjacent muscle, with or without increased vascularity on Doppler. Hyperechoic regions may correspond to fatty tissue. Infiltrative margins may be seen. On MRI, the lesions are usually of high T2 signal intensity with intermediate $\mathrm{T} 1$ signal intensity, but they may have a heterogeneous appearance due to fatty tissue around the blood vessels showing high $\mathrm{T} 1$ signal intensity. ${ }^{58}$ Intralesional hemorrhage may result in the presence of hemosiderin that will demonstrate low T2 signal with blooming artifact on gradient-echo sequences. Following IV gadolinium, there is avid enhancement with visualization of feeding vessels. Hemangiomas with arterial flow can be distinguished from arteriovenous malformations (AVMs) by the presence of solid parenchymal tissue and interarterial communications.

\section{Vascular Malformations}

Vascular malformations are not neoplasms and represent focal defective morphogenesis with a quiescent endothelium resulting in dysplastic vessels. ${ }^{58}$ Histologically, they are composed of irregular dilated vascular channels with a mature endothelium that has a normal rate of turnover. They are classified into four main categories: simple, combined, malformations of major named vessels, and syndrome-associated malformations. ${ }^{59}$ The simple and combined categories are derived from the vessel of origin that may be capillary, venous, arteriovenous, or lymphatic. These may be further broadly classified as slow- or high-flow lesions.

Vascular malformations do not involute but tend to grow in proportion with the patient. This growth may accelerate following trauma or during puberty or pregnancy. The imaging features depend on the subtype; venous malformations are the most common. ${ }^{59}$ US with Doppler is useful to delineate if a lesion belongs to the slow- or high-flow category, with arterial flow seen in the latter.

Capillary malformations are the equivalent of the port wine stain and tend to occur superficially involving the skin. A clinical diagnosis can typically be made. On imaging, skin thickening is seen, usually with no discernible mass or demonstrable vascular channels, or flow on Doppler. ${ }^{59}$

Venous malformations are composed of dilated slow-flowing vascular spaces and channels forming a venous network, with no solid tissue component apart from septations. ${ }^{58}$ They are typically seen in children and young adults who present with pain, swelling, and decreased function. On US, venous malformations have a hypoechoic or heterogeneous appearance in $80 \%$ of cases. ${ }^{59}$ Anechoic channels are present in $<50 \%$ of cases. Typically, the lesion is compressible, with slow refilling. Phleboliths appear as hyperechoic foci with posterior acoustic shadowing, and they can be readily confirmed on plain radiographs. On Doppler US, there is monophasic low-velocity flow. In up to $16 \%$ of venous malformations there is absent Doppler signal that may indicate thrombosis of the lesion (-Fig. 16 and -Fig. S2).

MRI demonstrates a lesion of high T2 signal and intermediate/low T1 signal, with susceptibility artifacts if there are areas of thrombosis and signal voids reflecting flow. ${ }^{60}$ Phleboliths are of low T1 and T2 signal. There is typically delayed enhancement with IV gadolinium (-Fig. 17 and -Fig. S3).

Lymphatic malformations are usually more infiltrative than the venous malformations and more likely to have fluid-fluid levels. ${ }^{61}$ Lymphatic malformations may be macrocystic and show septal enhancement with IV contrast, or microcystic, with no appreciable enhancement.

AVMs are high-flow vascular malformations with abnormal channels between arteries and veins. AVMs can be differentiated from arteriovenous fistulae by the presence of an intervening central nidus in the former. ${ }^{61}$ On US, 


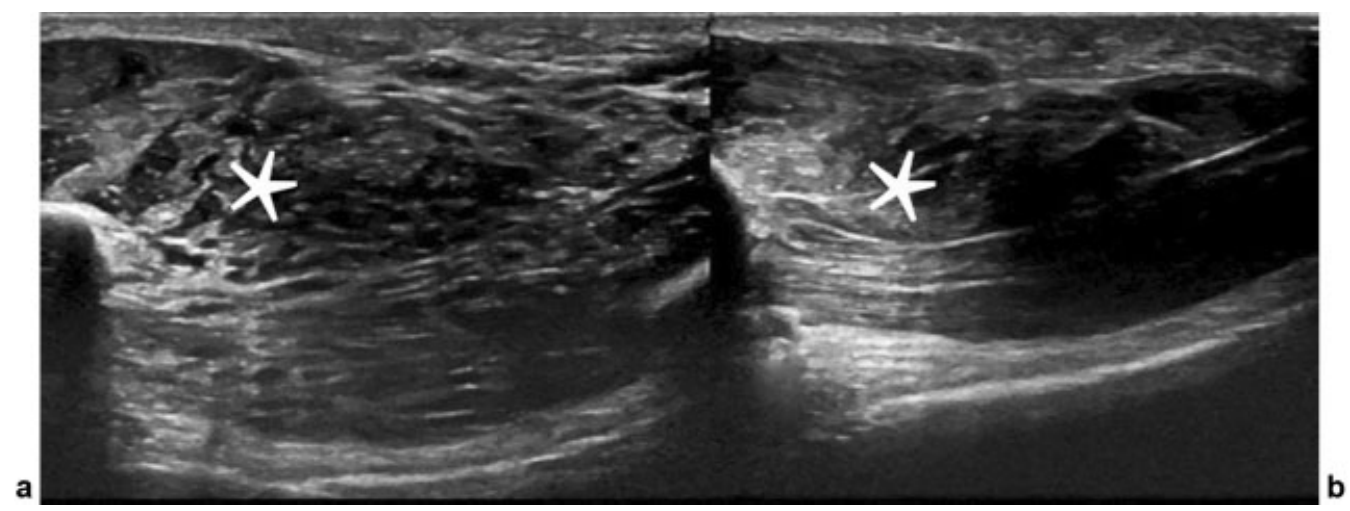

Fig. 16 Low-flow vascular malformation. (a) Ultrasound (US) demonstrating an infiltrating heterogeneous lesion of the thenar muscles (asterisk). (b) US demonstrating the normal appearance of the thenar eminence on the contralateral side (asterisk).

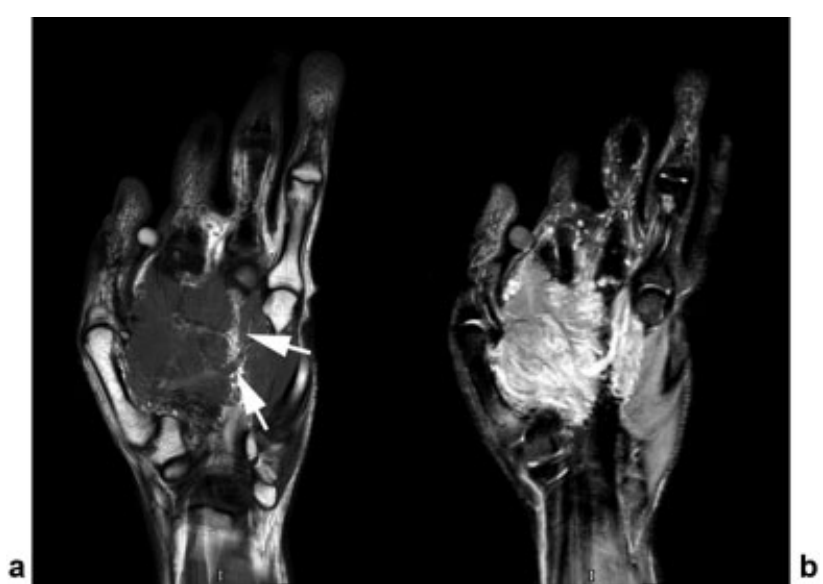

Fig. 17 Low-flow vascular malformation. (a) Coronal T1-weighted image demonstrating a prominent vessel (arrows). (b) Coronal short tau inversion recovery image demonstrating serpiginous high $\mathrm{T} 2$ signal infiltration of the thenar eminence.

enlarged vessels are seen, with high flow on Doppler interrogation. On spin-echo MRI, large vascular channels with flow voids are demonstrated with corresponding high T2 signal on flow-enhanced gradient-echo sequences. ${ }^{59}$ Intraosseous extension of vessels may be evident.

MR angiography may be useful to help classify lesions as slow or high flow. ${ }^{59}$ Identification of high-flow vascular structures with signal voids on both T1- and T2-weighted images excludes a slow-flow lesion. High-flow lesions demonstrate arterial feeding vessels with draining veins and enhance rapidly following IV contrast.

\section{Pericytic Tumors}

Pericytes, contractile cells that surround the endothelial cells of capillaries and veins, have a key role in angiogenesis, tissue homeostasis, vessel permeability, and blood pressure control. ${ }^{62}$ Pericytic/perivascular soft tissue tumors are generally composed of modified vascular smooth muscle cells and tend to grow in a circumferential fashion around blood vessels. In the hand, the most common pericytic tumors are glomus tumors and angioleiomyomas.

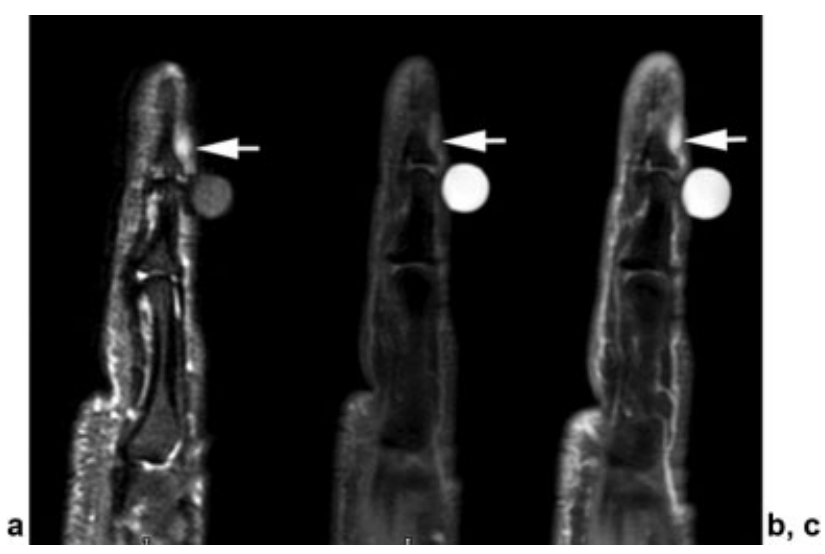

Fig. 18 Glomus tumor. (a) Sagittal short tau inversion recovery image demonstrating a high T2 signal lesion in the nail bed (arrow). (b) Sagittal T1 fat-saturated image showing an intermediate/low signal lesion (arrow). (c) Sagittal T1 fat-saturated image postgadolinium showing avid enhancement of the lesion (arrow).

\section{Glomus Tumors}

The glomus body is a specialized arteriovenous anastomosis in the dermis involved in thermoregulation, with a high concentration in the digits, palms, and soles. ${ }^{62}$ Glomus tumors are hamartomas of the glomus body, with up to $75 \%$ of cases occurring in the hand, specifically at the fingertips and subungual region. Patients are typically aged 20 to 40 years and present with a classic triad of exquisite pain, tenderness, and temperature sensitivity. ${ }^{63}$ There may be deformity of the overlying nail and associated discoloration of the tissues.

Imaging has an important role in determining the presence and location of glomus tumors. On US, a small ovoid nodule may be evident, often with underlying bony erosion. ${ }^{64}$ Most lesions are hypoechoic, with the remainder appearing of heterogeneous echogenicity. Characteristically there is prominent internal vascularity on Doppler interrogation, but this is not always present. ${ }^{63}$ On MRI, the nodule is of high T2 signal and intermediate or low T1 signal. ${ }^{65}$ Following gadolinium administration, there is avid enhancement, but this may not be homogeneous (-Fig. 18). 


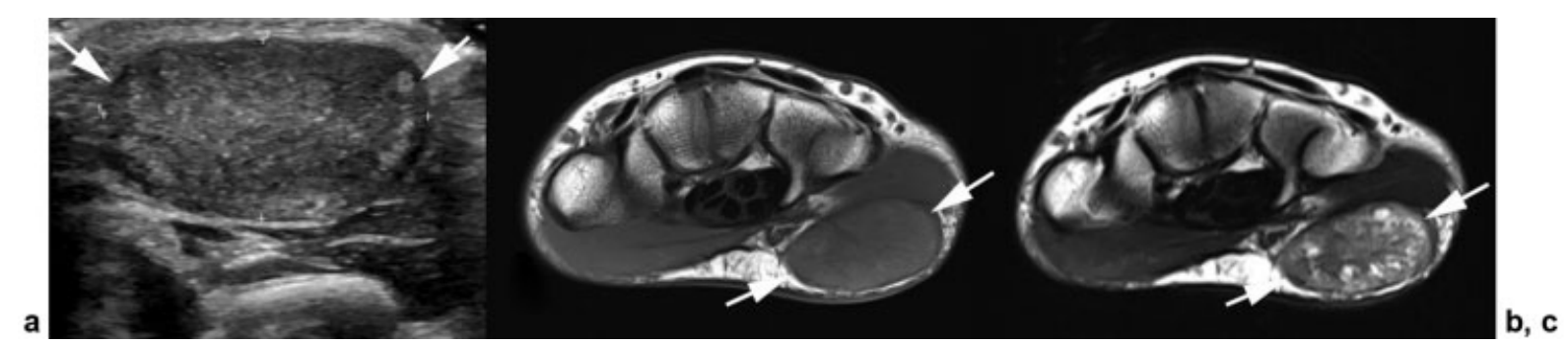

Fig. 19 Angioleiomyoma. (a) Transverse ultrasound image demonstrating a well-defined ovoid mass with minor internal heterogeneity (arrows). (b) Axial T1-weighted image demonstrating a well-defined ovoid mass (arrows) in the deep subcutaneous tissues that is mildly hyperintense to adjacent muscle. (c) Axial T2-weighted image demonstrating a heterogeneous mass with linear and ovoid high T2 signal areas.

\section{Angioleiomyomas}

Angioleiomyomas are benign pericytic tumors arising from smooth muscle of blood vessels without elastic fibers. They occur throughout the body, with most occurring in the extremities (89\%), usually the lower limb. ${ }^{66}$ They typically occur in patients aged 20 to 40 , affecting women more than men. They usually present as painful masses due to active contraction of smooth muscle resulting in ischemia.

On imaging, they appear as well-defined round or ovoid masses in a subcutaneous or dermal location. On US, they tend to be of homogeneous low echogenicity with increased vascularity on Doppler. ${ }^{43}$ On MRI, they are usually isointense or slightly hyperintense to skeletal muscle on T1-weighted images with a heterogeneous appearance on T2-weighted images. ${ }^{66}$ There may be areas of internal linear and branching high T2 signal representing bundles of smooth muscle cells surrounding capillary-size vessels. Following IV gadolinium, there may be homogeneous or heterogeneous enhancement ${ }^{4}$ (-Fig. 19).

\section{Sarcomas}

Soft tissue sarcomas of the hand are rare, comprising 2 to $4 \%$ of limb and trunk tumors. ${ }^{67}$ The most frequent tumor subtypes are liposarcoma, synovial sarcoma, conventional epithelioid sarcoma, rhabdomyosarcoma, and clear cell sarcoma. Differentiating between the different subtypes is difficult because they can share clinical, imaging, and histologic features.
Synovial sarcomas are derived from primitive mesenchymal cells rather than from the synovium. They usually present in the third to fourth decade. They typically occur around large joints but tend not to be intra-articular, with most occurring in the lower extremity and up to $25 \%$ occurring in the upper limb. ${ }^{68}$ In the hand, they usually present as a slow-growing mass. About a third of synovial sarcomas demonstrate calcification on plain radiographs. Small lesions may have well-defined margins and a homogeneous appearance, often suggesting a benign mass. ${ }^{68}$ Larger lesions spread between compartments, making wide local excision difficult. On T2-weighted images, there may be heterogeneity reflecting hemorrhage. ${ }^{69}$ Fluid-fluid levels may be present, and there may be a multiloculated appearance with internal septae. The "triple sign" has been described with high T2 signal intensity due to hemorrhage or necrosis, intermediate signal intensity due to solid cellular components, and low signal due to calcifications or fibrosis. ${ }^{70}$ On T1-weighted images, they are usually isointense to skeletal muscle. Adjacent bone may become invaded ( $\mathbf{- F i g . ~} 20$ and $\boldsymbol{\sim}$ Figs. $\mathbf{S 4}$ and $\mathbf{5 5}$ ).

Epithelioid is the term used to describe cells that have a round or polygonal appearance with abundant cytoplasm, similar in appearance to epithelial cells. ${ }^{10}$ Epithelioid sarcomas are of uncertain cellular lineage. Proximal-type epithelioid sarcomas occur mainly in the pelvis, perineum, and genitalia, whereas the distal type affects the extremities, with $60 \%$ involving the flexor regions of the upper limb. ${ }^{67}$ They are the most common soft tissue malignancies of the hand in

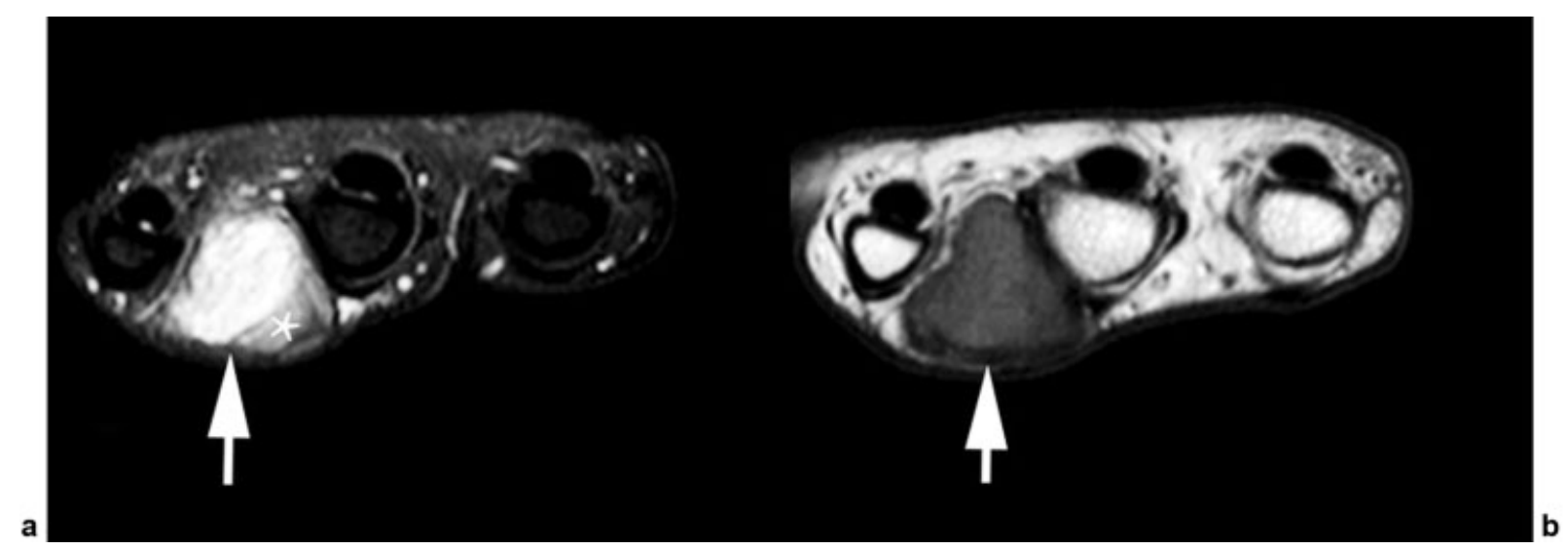

Fig. 20 Synovial sarcoma. (a) Axial proton-density fat-saturated image demonstrating a heterogeneous high T2 signal mass (arrow) with a region of lower T2 signal (asterisk). (b) Axial T1-weighted image demonstrating an intermediate signal mass (arrow) with a low signal rim on its superficial aspect. 
young adults, affecting males twice as often as females. They present as slow-growing masses that may be multiple and may ulcerate, sometimes mimicking infection. ${ }^{71}$ A typical finding is of propagation along fascial planes, nerves, and tendons. Regional lymphadenopathy may occur. The US features are of a nonspecific infiltrating mass with increased vascularity. On MRI, the mass is isointense to muscle on T1-weighted images with regions of heterogeneity due to hemorrhage. ${ }^{71}$ On T2-weighted images, the mass is of high T2 signal with areas of central necrosis and peritumoral edema. Speckled calcifications may be seen on radiographs.

Rhabdomyosarcomas arise from embryonic mesenchyme with the potential to differentiate into skeletal muscle. ${ }^{72}$ They constitute 4 to $8 \%$ of all childhood malignancies but are rare in adults. The uncommon pleomorphic subtype occurs almost exclusively in adults involving the extremities. Rhabdomyosarcomas tend to infiltrate the soft tissues and may encase tendons and neurovascular bundles. The imaging findings may be indistinguishable from other sarcomas.

Clear cell sarcoma is a very rare deep-seated tumor of melanocytic differentiation, typically involving tendons and aponeuroses of the distal extremities of young adults and presenting as a small tender mass. ${ }^{73}$ There are similarities to malignant melanoma, and it has been designated "malignant melanoma of soft parts," but there is a distinct cytogenetic abnormality. Tumors containing melanin may appear hyperintense on T1-weighted sequences and hypointense on T2-weighted sequences. ${ }^{73}$ Tumors without significant melanin, in contrast, typically demonstrate intermediate/ low T1 signal and high T2 signal.

\section{Management of Soft Tissue Sarcomas}

The initial management of soft tissue sarcomas varies across different countries. However, certain guiding principles should ensure optimum patient outcomes. When a sarcoma is suspected, the patient should be referred to a regional sarcoma multidisciplinary team for further management. ${ }^{74,75}$ US by a musculoskeletal radiologist should be considered as a first-line investigation. ${ }^{74}$ Local staging with MRI, which involves imaging of the entire limb, and core biopsy of the lesion should be performed. When there is histologic confirmation, systemic staging should be performed. At a minimum this should include CT of the chest, but emerging evidence suggests that whole-body staging is ideally achieved by PET/CT because it combines both metabolic and anatomical imaging. ${ }^{76}$

\section{Conflict of Interest}

None declared.

\section{References}

1 Capelastegui A, Astigarraga E, Fernandez-Canton G, Saralegui I, Larena JA, Merino A. Masses and pseudomasses of the hand and wrist: MR findings in 134 cases. Skeletal Radiol 1999;28(09): 498-507

2 Stack HG. Tumors of the hand. BMJ 1960;1(5177):919-922

3 Teh J, Whiteley G. MRI of soft tissue masses of the hand and wrist. Br J Radiol 2007;80(949):47-63
4 Sookur PA, Saifuddin A. Indeterminate soft-tissue tumors of the hand and wrist: a review based on a clinical series of 39 cases. Skeletal Radiol 2011;40(08):977-989

5 Teh J. Ultrasound of soft tissue masses of the hand. J Ultrason 2012;12(51):381-401

6 Bianchi S, Della Santa D, Glauser T, Beaulieu J-Y, van Aaken J. Sonography of masses of the wrist and hand. AJR Am J Roentgenol 2008;191(06):1767-1775

7 Khaled W, Drapé JL. MRI of wrist and hand masses. Diagn Interv Imaging 2015;96(12):1238-1246

8 Vanhoenacker FM, Eyselbergs M, Van Hul E, Van Dyck P, De Schepper AM. Pseudotumoural soft tissue lesions of the hand and wrist: a pictorial review. Insights Imaging 2011;2(03): 319-333

9 Calleja M, Dimigen M, Saifuddin A. MRI of superficial soft tissue masses: analysis of features useful in distinguishing between benign and malignant lesions. Skeletal Radiol 2012;41(12): 1517-1524

10 Kuhn KJ, Cloutier JM, Boutin RD, Steffner R, Riley G. Soft tissue pathology for the radiologist: a tumor board primer with 2020 WHO classification update. Skeletal Radiol 2020(August):1-14

11 Gude W, Morelli V. Ganglion cysts of the wrist: pathophysiology, clinical picture, and management. Curr Rev Musculoskelet Med 2008;1(3-4):205-211

12 Teefey SA, Dahiya N, Middleton WD, Gelberman RH, Boyer MI. Ganglia of the hand and wrist: a sonographic analysis. AJR Am J Roentgenol 2008;191(03):716-720

13 Balazs GC, Dworak TC, Tropf J, Nanos GP III, Tintle SM. Incidence and Risk Factors for Volar Wrist Ganglia in the U.S. Military and Civilian Populations. J Hand Surg Am 2016;41(11):1064-1070

14 Andrén L, Eiken O. Arthrographic studies of wrist ganglions. J Bone Joint Surg Am 1971;53(02):299-302

15 Wang G, Jacobson JA, Feng FY, Girish G, Caoili EM, Brandon C. Sonography of wrist ganglion cysts: variable and noncystic appearances. J Ultrasound Med 2007;26(10):1323-1328; quiz 1330-1331

16 Anderson SE, Steinbach LS, Stauffer E, Voegelin E. MRI for differentiating ganglion and synovitis in the chronic painful wrist. AJR Am J Roentgenol 2006;186(03):812-818

17 Vanhoenacker FM, Desimpel J, Mespreuve M, Tagliafico A. Accessory muscles of the extremities. Semin Musculoskelet Radiol 2018;22(03):275-285

18 Sookur PA, Naraghi AM, Bleakney RR, Jalan R, Chan O, White LM. Accessory muscles: anatomy, symptoms, and radiologic evaluation. Radiographics 2008;28(02):481-499

19 Stevens KJ, Theologis T, McNally EG, Stevens K. Imaging of plantthorn synovitis. Skeletal Radiol 2000;29(10):605-608

20 Horton LK, Jacobson JA, Powell A, Fessell DP, Hayes CW. Sonography and radiography of soft-tissue foreign bodies. AJR Am J Roentgenol 2001;176(05):1155-1159

21 Jacobson JA, Powell A, Craig JG, Bouffard JA, van Holsbeeck MT. Wooden foreign bodies in soft tissue: detection at US. Radiology 1998;206(01):45-48

22 Monu JUV, McManus CM, Ward WG, Haygood TM, Pope TL Jr, Bohrer SP. Soft-tissue masses caused by long-standing foreign bodies in the extremities: MR imaging findings. AJR Am J Roentgenol 1995;165(02):395-397

23 Jin W, Ryu KN, Kim GY, Kim HC, Lee JH, Park JS. Sonographic findings of ruptured epidermal inclusion cysts in superficial soft tissue: emphasis on shapes, pericystic changes, and pericystic vascularity. J Ultrasound Med 2008;27(02):171-176; quiz $177-178$

24 Hoang VT, Trinh CT, Nguyen CH, Chansomphou V, Chansomphou V, Tran TTT. Overview of epidermoid cyst. Eur J Radiol Open 2019; 6:291-301

25 Teh J, McQueen F, Eshed I, Plagou A, Klauser A. Advanced imaging in the diagnosis of gout and other crystal arthropathies. Semin Musculoskelet Radiol 2018;22(02):225-236 
26 Ogdie A, Taylor WJ, Neogi T, et al. Performance of ultrasound in the diagnosis of gout in a multicenter study: comparison with monosodium urate monohydrate crystal analysis as the gold standard. Arthritis Rheumatol 2017;69(02):429-438

27 Yu Z, Mao T, Xu Y, et al. Diagnostic accuracy of dual-energy CT in gout: a systematic review and meta-analysis. Skeletal Radiol 2018;47(12):1587-1593

28 Starok M, Eilenberg SS, Resnick D. Rheumatoid nodules: MRI characteristics. Clin Imaging 1998;22(03):216-219

29 Takashima S, Ota M. Methotrexate-induced nodulosis. CMAJ 2015;187(10):E327

30 Sudoł-Szopińska I, Jans L, Teh J. Rheumatoid arthritis: what do MRI and ultrasound show. J Ultrason 2017;17(68):5-16

31 WHO Classification of Tumours Editorial Board. WHO Classification of Tumours of Soft Tissue and Bone. 5th ed. Lyon, France: IARC Press; 2020

32 Murphey MD, Rhee JH, Lewis RB, Fanburg-Smith JC, Flemming DJ, Walker EA. Pigmented villonodular synovitis: radiologic-pathologic correlation. Radiographics 2008;28(05):1493-1518

33 Middleton WD, Patel V, Teefey SA, Boyer MI. Giant cell tumors of the tendon sheath: analysis of sonographic findings. AJR Am J Roentgenol 2004;183(02):337-339

34 Ferrando PM, Garagnani L, Eckersley R, Weir J, Katsarma E. Lipomatous tumours of the hand and wrist. A series of 25 cases and review of the literature. Ann Ital Chir 2014;85(06):587-592

35 Rahmani G, McCarthy P, Bergin D. The diagnostic accuracy of ultrasonography for soft tissue lipomas: a systematic review. Acta Radiol Open 2017;6(06):2058460117716704

36 Bancroft LW, Kransdorf MJ, Peterson JJ, O'Connor MI. Benign fatty tumors: classification, clinical course, imaging appearance, and treatment. Skeletal Radiol 2006;35(10):719-733

37 Silverman TA, Enzinger FM. Fibrolipomatous hamartoma of nerve. A clinicopathologic analysis of 26 cases. Am J Surg Pathol 1985;9 (01):7-14

38 Brodwater BK, Major NM, Goldner RD, Layfield LJ. Macrodystrophia lipomatosa with associated fibrolipomatous hamartoma of the median nerve. Pediatr Surg Int 2000;16(03):216-218

39 Whittle C, Schonstedt V, Schiappacasse G. Fibrolipomatous hamartoma and its ultrasound diagnosis: case series and review of the literature. Ultrasound Q 2014;30(04):282-286

40 Marom EM, Helms CA. Fibrolipomatous hamartoma: pathognomonic on MR imaging. Skeletal Radiol 1999;28(05):260-264

41 Suzuki K, Yasuda T, Suzawa S, Watanabe K, Kanamori M, Kimura T. Fibroma of tendon sheath around large joints: clinical characteristics and literature review. BMC Musculoskelet Disord 2017;18 (01):376

42 Carter JM, Wang X, Dong J, Westendorf J, Chou MM, Oliveira AM. USP6 genetic rearrangements in cellular fibroma of tendon sheath. Mod Pathol 2016;29(08):865-869

43 Ogata D, Takeji M, Murakami T, Yanagisawa H, Kuramochi A, Tsuchida T. Comparison of ultrasonographic findings of schwannomas and angioleiomyomas. J Dermatol 2018;45(07):837-843

$44 \mathrm{Ge}$ Y, Guo G, You Y, et al. Magnetic resonance imaging features of fibromas and giant cell tumors of the tendon sheath: differential diagnosis. Eur Radiol 2019;29(07):3441-3449

45 Molenkamp S, van Straalen RJM, Werker PMN, Broekstra DC. Imaging for Dupuytren disease: a systematic review of the literature. BMC Musculoskelet Disord 2019;20(01):224

46 Morris G, Jacobson JA, Kalume Brigido M, Gaetke-Udager K, Yablon CM, Dong Q. Ultrasound features of palmar fibromatosis or Dupuytren contracture. J Ultrasound Med 2019;38(02): 387-392

47 Yacoe ME, Bergman AG, Ladd AL, Hellman BH. Dupuytren's contracture: MR imaging findings and correlation between MR signal intensity and cellularity of lesions. AJR Am J Roentgenol 1993;160(04):813-817

48 Murphey MD, Smith WS, Smith SE, Kransdorf MJ, Temple HT. From the archives of the AFIP. Imaging of musculoskeletal neuro- genic tumors: radiologic-pathologic correlation. Radiographics 1999;19(05):1253-1280

49 Ryu JA, Lee SH, Cha E-Y, Kim TY, Kim S-M, Shin MJ. Sonographic differentiation between schwannomas and neurofibromas in the musculoskeletal system. J Ultrasound Med 2015;34(12): 2253-2260

50 Beggs I. Sonographic appearances of nerve tumors.J Clin Ultrasound 1999;27(07):363-368

51 Beggs I. The ring sign: a new ultrasound sign of peripheral nerve tumours. Clin Radiol 1998;53(11):849-850

52 Suh JS, Abenoza P, Galloway HR, Everson LI, Griffiths HJ. Peripheral (extracranial) nerve tumors: correlation of MR imaging and histologic findings. Radiology 1992;183(02):341-346

53 Lee SK, Kim JY, Lee YS, Jeong HS. Intramuscular peripheral nerve sheath tumors: schwannoma, ancient schwannoma, and neurofibroma. Skeletal Radiol 2020;49(06):967-975

54 Mautner VF, Friedrich RE, von Deimling A, et al. Malignant peripheral nerve sheath tumours in neurofibromatosis type 1 : MRI supports the diagnosis of malignant plexiform neurofibroma. Neuroradiology 2003;45(09):618-625

55 Ferner RE, Golding JF, Smith M, et al. [18F]2-fluoro-2-deoxy-Dglucose positron emission tomography (FDG PET) as a diagnostic tool for neurofibromatosis 1 (NF1) associated malignant peripheral nerve sheath tumours (MPNSTs): a long-term clinical study. Ann Oncol 2008;19(02):390-394

56 Society for the Study of Vascular Anomalies. ISSVA Classification of Vascular Anomalies. 2018 Available at: ssva.org/classification. Accessed December 15, 2020

57 Ernemann U, Kramer U, Miller S, et al. Current concepts in the classification, diagnosis and treatment of vascular anomalies. Eur J Radiol 2010;75(01):2-11

58 Merrow AC, Gupta A, Patel MN, Adams DM. 2014 Revised Classification of Vascular Lesions from the International Society for the Study of Vascular Anomalies: Radiologic-Pathologic Update. Radiographics 2016;36(05):1494-1516

59 Drapé JL, Feydy A, Guerini H, et al. Vascular lesions of the hand. Eur J Radiol 2005;56(03):331-343

60 Moukaddam H, Pollak J, Haims AH. MRI characteristics and classification of peripheral vascular malformations and tumors. Skeletal Radiol 2009;38(06):535-547

61 Fayad LM, Hazirolan T, Bluemke D, Mitchell S. Vascular malformations in the extremities: emphasis on MR imaging features that guide treatment options. Skeletal Radiol 2006;35(03): 127-137

62 Morey VM, Garg B, Kotwal PP. Glomus tumours of the hand: review of literature. J Clin Orthop Trauma 2016;7(04):286-291

63 Fan Z, Wu G, Ji B, et al. Color Doppler ultrasound morphology of glomus tumors of the extremities. Springerplus 2016;5(01):1319

64 Fornage BD. Glomus tumors in the fingers: diagnosis with US. Radiology 1988;167(01):183-185

65 Al-Qattan MM, Al-Namla A, Al-Thunayan A, Al-Subhi F, El-Shayeb AF. Magnetic resonance imaging in the diagnosis of glomus tumours of the hand. J Hand Surg [Br] 2005;30(05):535-540

66 Hwang JW, Ahn JM, Kang HS, Suh JS, Kim SM, Seo JW. Vascular leiomyoma of an extremity: MR imaging-pathology correlation. AJR Am J Roentgenol 1998;171(04):981-985

67 McPhee M, McGrath BE, Zhang P, Driscoll D, Gibbs J, Peimer C. Soft tissue sarcoma of the hand. J Hand Surg Am 1999;24(05): 1001-1007

68 Murphey MD, Gibson MS, Jennings BT, Crespo-Rodríguez AM Fanburg-Smith J, Gajewski DA. From the archives of the AFIP: imaging of synovial sarcoma with radiologic-pathologic correlation. Radiographics 2006;26(05):1543-1565

69 Morton MJ, Berquist TH, McLeod RA, Unni KK, Sim FH. MR imaging of synovial sarcoma. AJR Am J Roentgenol 1991;156(02):337-340

70 Jones BC, Sundaram M, Kransdorf MJ. Synovial sarcoma: MR imaging findings in 34 patients. AJR Am J Roentgenol 1993;161 (04):827-830 
71 Romero JA, Kim EE, Moral IS. MR characteristics of epithelioid sarcoma. J Comput Assist Tomogr 1994;18(06):929-931

72 Casanova M, Meazza C, Favini F, Fiore M, Morosi C, Ferrari A. Rhabdomyosarcoma of the extremities: a focus on tumors arising in the hand and foot. Pediatr Hematol Oncol 2009;26(05): 321-331

73 De Beuckeleer LH, De Schepper AM, Vandevenne JE, et al. MR imaging of clear cell sarcoma (malignant melanoma of the soft parts): a multicenter correlative MRI-pathology study of 21 cases and literature review. Skeletal Radiol 2000;29(04):187-195
74 Noebauer-Huhmann IM, Weber MA, Lalam RK, et al. Soft tissue tumors in adults: ESSR-approved guidelines for diagnostic imaging. Semin Musculoskelet Radiol 2015;19(05):475-482

75 Dangoor A, Seddon B, Gerrand C, Grimer R, Whelan J, Judson I. UK guidelines for the management of soft tissue sarcomas. Clin Sarcoma Res 2016;6(01):20

76 Macpherson RE, Pratap S, Tyrrell H, et al. Retrospective audit of 957 consecutive ${ }^{18} \mathrm{~F}$-FDG PET-CT scans compared to CT and MRI in 493 patients with different histological subtypes of bone and soft tissue sarcoma. Clin Sarcoma Res 2018;8(01):9 